Journal of Nature, Life

and Applied Sciences

Volume (5), Issue (3) : 30 Sep 2021

P: 87 - 107
AJSRP

ISSN: 2522-3356

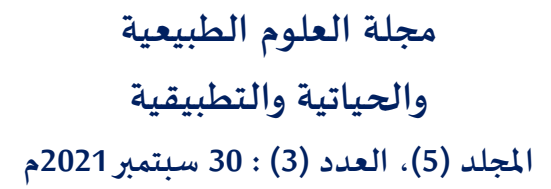

ص: 87 - 107

\title{
Spatial and temporal variation of vegetation cover in Al-Soudah area and its relationship to precipitation during the period (2014- 2018 AD) using remote sensing and geographic information systems
}

\author{
Fadi Abdullah alanazi \\ Yaser Rashed Alzannan \\ Faten Hamed Nahas
}

College of Art || King Saud university || KSA

\begin{abstract}
Souda is one of the important regions in Saudi Arabia in terms of spatial and temporal changes in vegetation cover; It includes the National Park, which is a leading tourist destination and one of the most beautiful parks in it.

by tracking the spatial and temporal changes of vegetation cover by integrating remote sensing and geographic information systems, through the application of the modified soil vegetation index MSAVI during the period (2014- 2018), it became clear the decrease in the quantity and density of vegetation cover in the area. Thus, the study concluded that this indicator is one of the best indicators that can be used to extract vegetation cover from satellite images.
\end{abstract}

Keywords: Modified Soil- Adjusted Vegetation Index (MSAVI), Souda, Bare soil, Radiometric Calibration, spatial resolution.

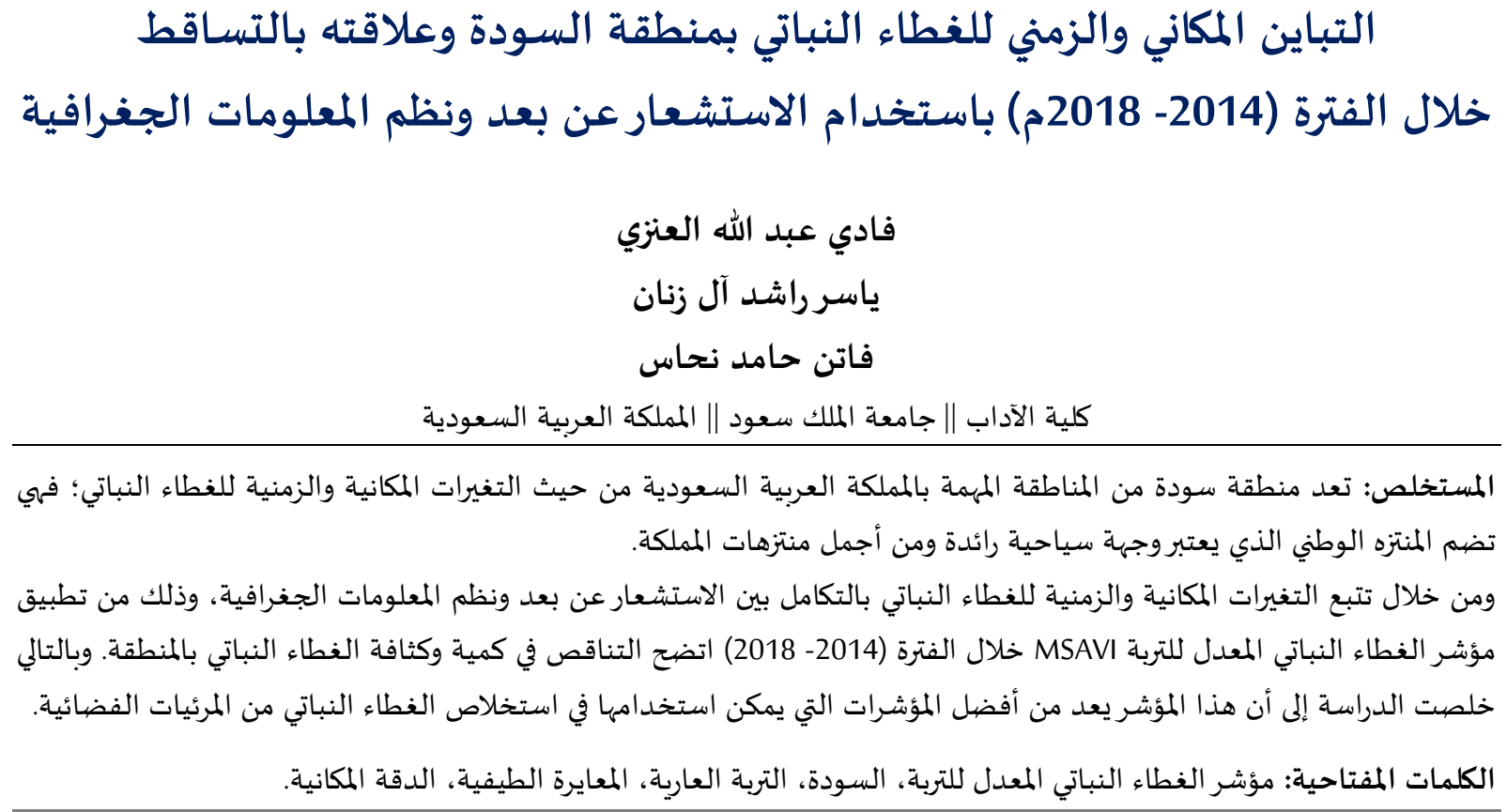


يعبر الغطاء النباتي عن الشكل النهائي للظروف البيئية بعناصرها المختلفة من تربة وطبوغرافية سطح الأرض والمناخ وغيرها، وبحسب اختلاف خصائص التربة والمناخ على سطح الأرض تختلف أشكال وصور النبات

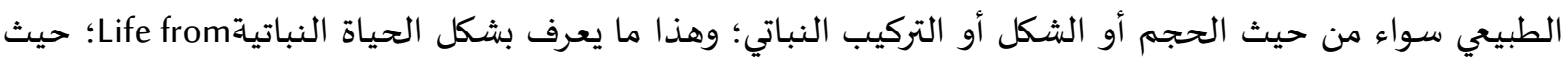

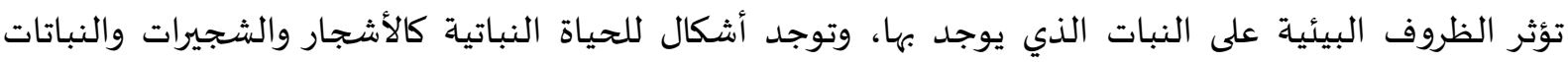

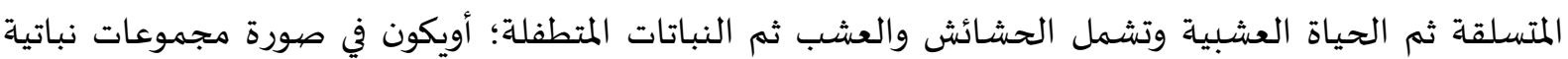

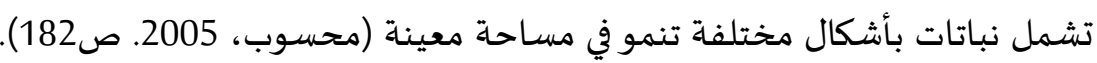

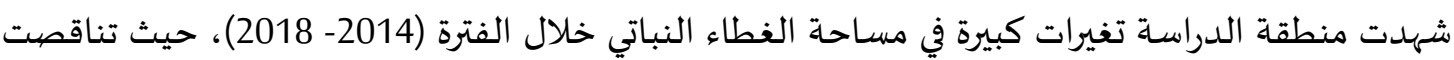

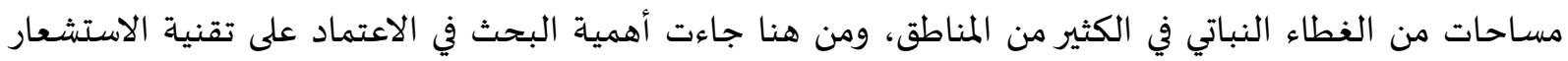

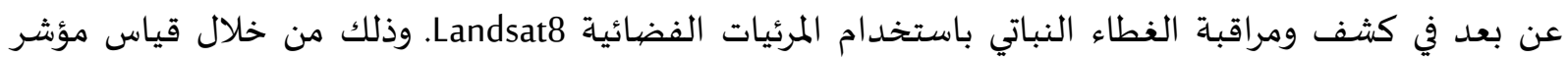

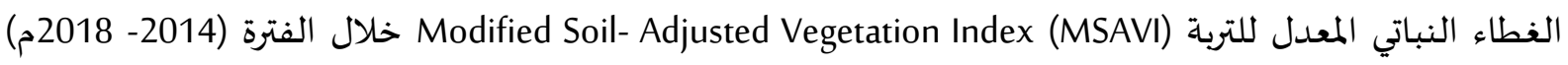
بالتكامل التطبيقي بين نظم المعلومات الجغرافية والاستشعار عن بعد، وذلك للوقوف على الوضع الراهن للغطاء

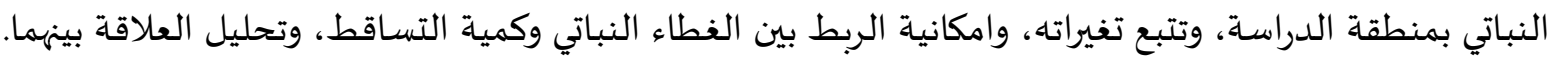

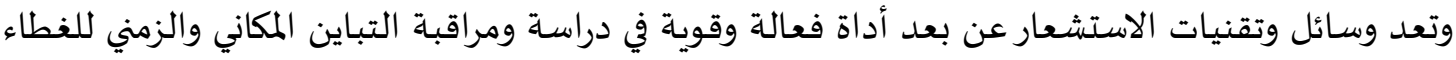

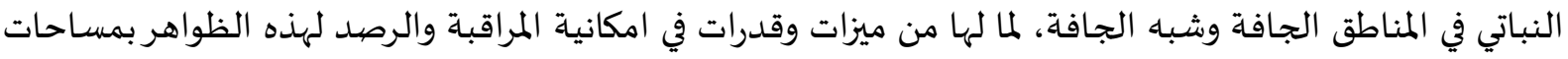

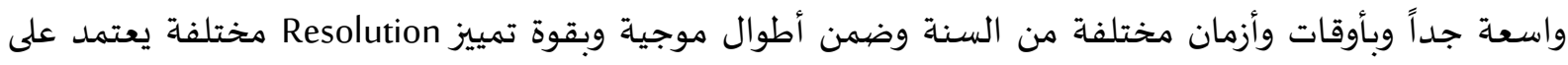

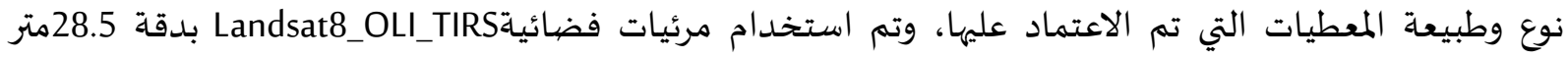

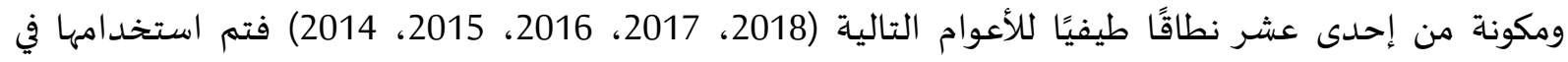

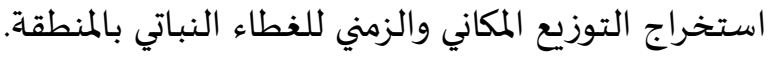
الكلمات المفتاحية: مؤشر الغطاء النباتي المعدل للتربة، الاستشعار عن بعد، نظم المعلومات الجغرافية،

منطقة السودة.

\section{أولاً: موقع وحدود منطقة الدراسة:}

تقع منطقة السودة في موقع متوسط بين محافظتي أبها ورجال ألمع؛ حيث يقع الجانب الشرقي منها

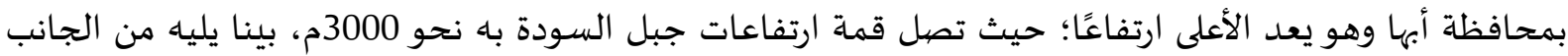
الغربي نطاق محافظة رجال ألمع وينخفض منسوبه بشكل كبير مقارنة بالجانب الشان الشرقي.

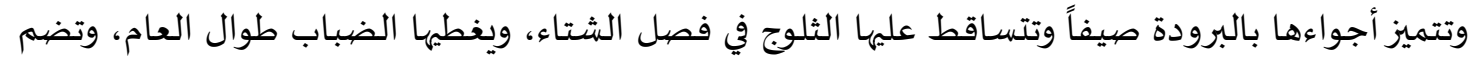
المنتزه الوطني الذي يعتبر وجهة سياحية رائعة للتخييم وهواة المشي والتسلق الجبلي، كما أصبحت السودة وجهات بهابة

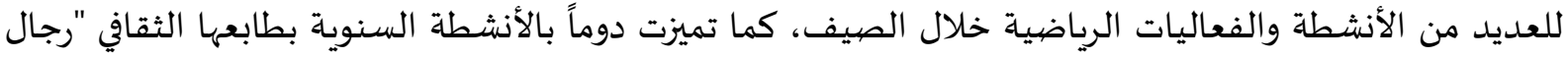

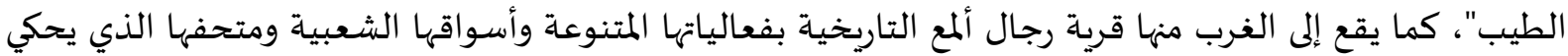
قصية المنطقة.

ويعد منتزه السودة أجمل منتزهات المملكة العربية السعودية، حيث تنتشر في الجبل أشجار العرعر

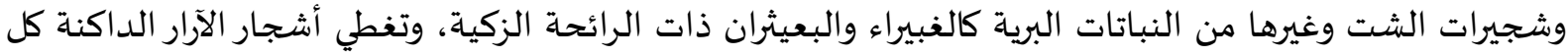

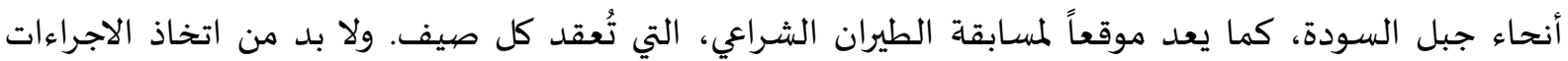
اللازمة للمحافظة على التنوع البيولوبي في هذه المنطقة. 


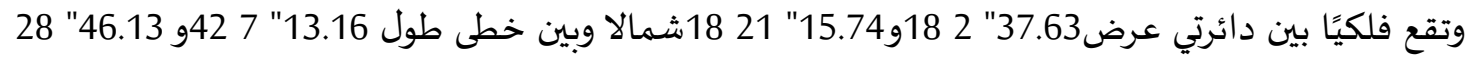

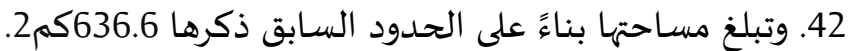

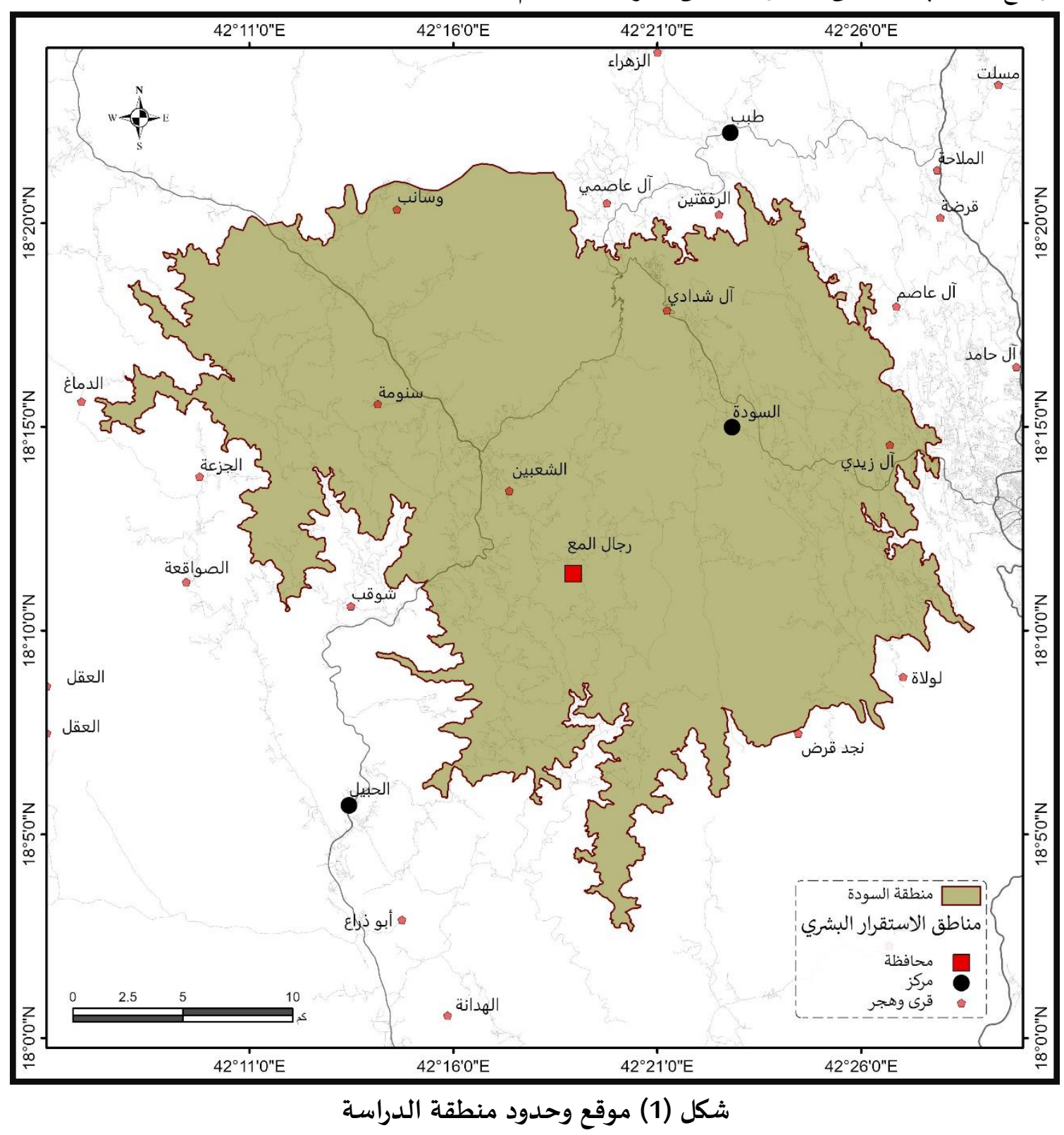

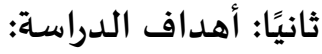

1- قياس مؤشر الغطاء النباتي المعدل للتربة بمنطقة السودة لتحديد التباين المكاني للغطاء النباتي. 2- دراسة التباين الزمني للغطاء النباتي بمنطقة الدراسة خلال الفترة (2014- 2018).

3- قياس العلاقات المكانية بين توزيع وتباين الغطاء النباتي وعلاقته بالتساقط.

4- الوقوف على الصورة التوزيعية الحالية للغطاء النباتي بمنطقة السودة، ومعرفة دور نظم المعلومات الجغرافية

والاستشعار عن بعد في دراسة التوزيع المكاني والزمني للغطاء النباتي بالمنطقة.

ثالثًا: مناهج الدراسة وأسالييها:

اعتمدت الدراسة على مجموعة من المناهج والأسـاليب منها: 
1- منهج شمولية الواقع الجغرافي: ويسمح هذا المنهج بدراسـة المتغيرات الكلية والجزئية، العامة والخاصة، التي

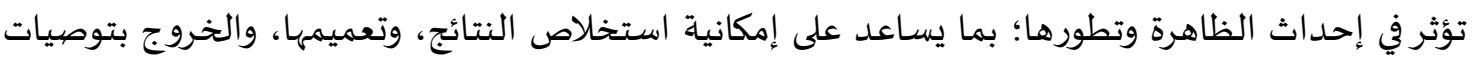

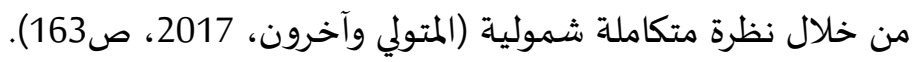

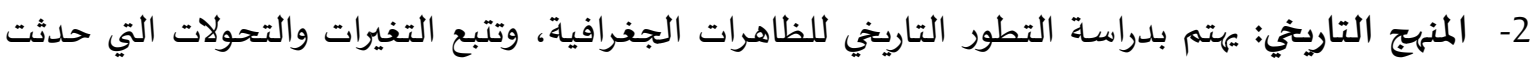

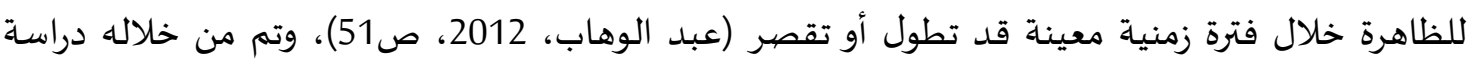
تغير الغطاء النباتي بمنطقة الدراسة خلال الفترة (2014- 2018). 3- المنهج الإقليمي: حيث تعد منطقة السودة وحدة جغرافية واضحة المعالم التي تميزها عما يجاورها، وبالتالي

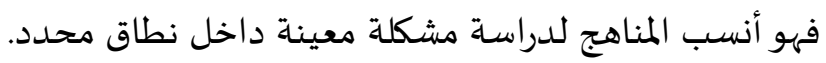

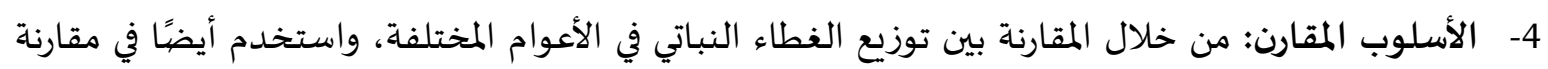

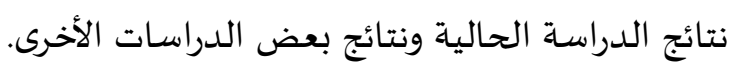
5- الأسلوب الكمي: تطبيق مؤشر على المرئيات الفضائية لاستخراج الغطاء النباتي، وانشاء العلاقات المكانية

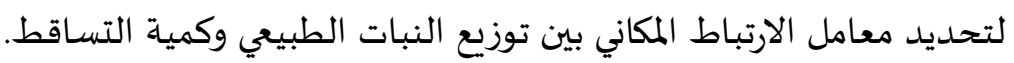

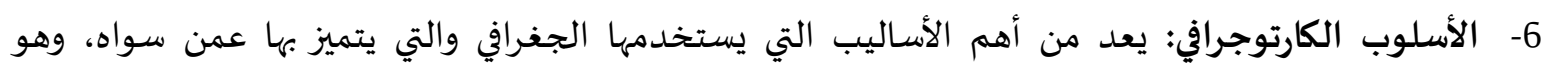

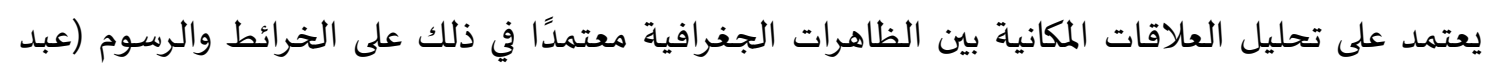

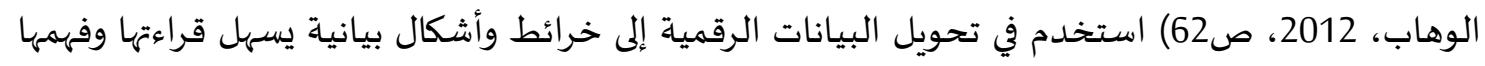
باستخدام برامج الاستشعار عن بعد ونظم المعلومات الجغرافية. رابعًا: مصادر الدراسة:

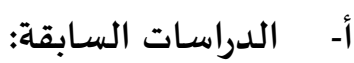

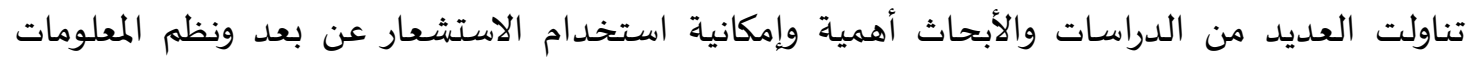

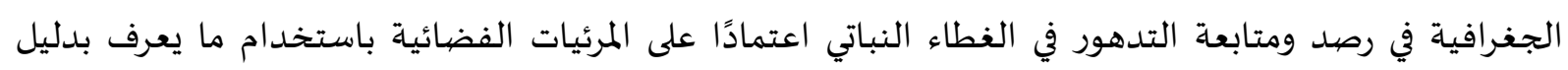

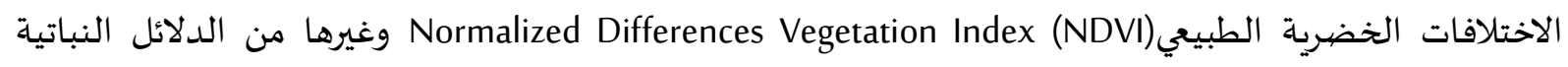
المستخدمة في دراسة التباين المكاني للغطاء النباتي يتم حسابها ضمن الأطوال الموجية المختلفة للمرئيات الفضائية،

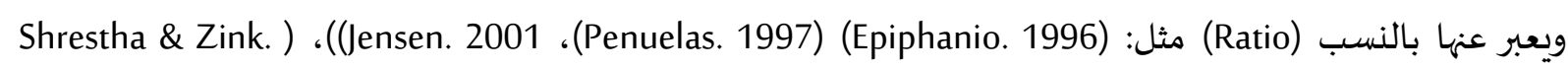

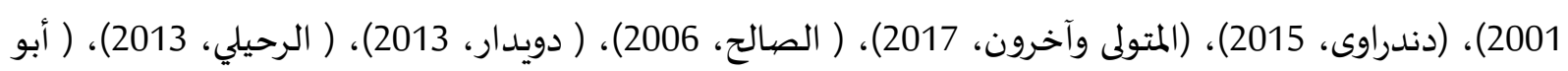
علي، 2016)، (المحمد وآخرون، 2018)، (دنداو، (المتوب واخون

ب- المرئيات الفضيائية: اعتمدت الدراسة على مرئيات Landsat 8التي تنتمى إلى سلسلة الأقمار الصناعية التي أطلقتها وكالة ناسا

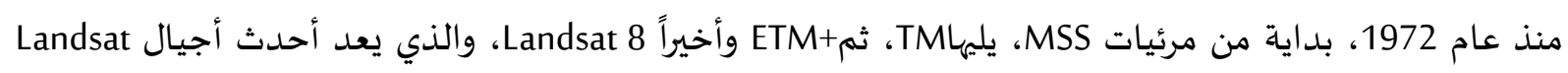

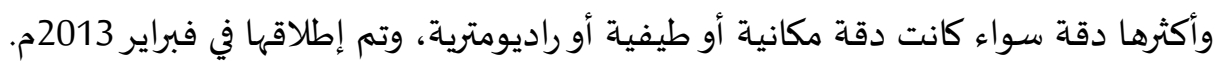


وتتكون هذه المرئيات من 11 نطاقاً طيفياً كما يوضح جدول (1) الذي يشير إلى أن هناك خمسة نطاقات

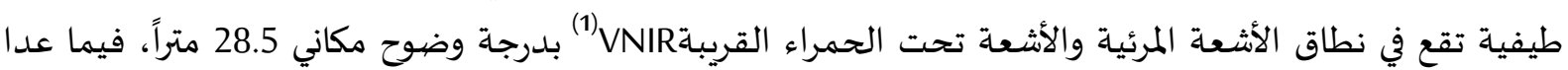

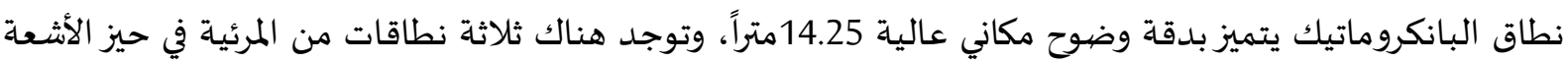

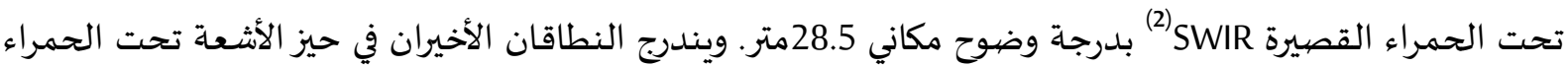

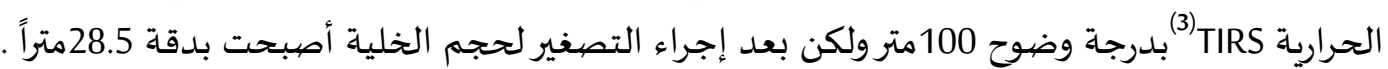

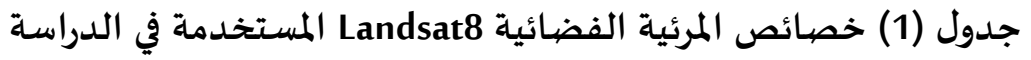

\begin{tabular}{|c|c|c|c|}
\hline ن نطاق الطول الموبي & الدقة المكانية (م) & الطول الموجي (ميكرومتر) & رقم النطاق(Band) \\
\hline \multirow{6}{*}{ VNIR } & \multirow{5}{*}{28.5} & $0.45-0.43$ & 1 \\
\hline & & $0.51-0.45$ & (Blue ) 2 \\
\hline & & $0.59-0.53$ & (Green) 3 \\
\hline & & $0.67-0.64$ & (Red) 4 \\
\hline & & $0.88-0.85$ & Near Infrared (NIR)) 5 \\
\hline & 14.25 & $0.68-0.50$ & 8 \\
\hline \multirow{3}{*}{ SWIR } & \multirow{3}{*}{28.5} & $1.65-1.57$ & 6 \\
\hline & & $2.29-2.11$ & 7 \\
\hline & & $1.38-1.36$ & 9 \\
\hline \multirow{2}{*}{ TIRS } & \multirow{2}{*}{ (28.5) 100} & $11.19-10.6$ & 10 \\
\hline & & $12.51-11.5$ & 11 \\
\hline
\end{tabular}

Source: Pour and Hashim.2015. p.156.

خامسًا: منهجية الدراسة:

اعتمدت الدراسة على تقنية الاستشعار عن بعد في كشف ومراقبة الغطاء النباتي باستخدام المرئيات

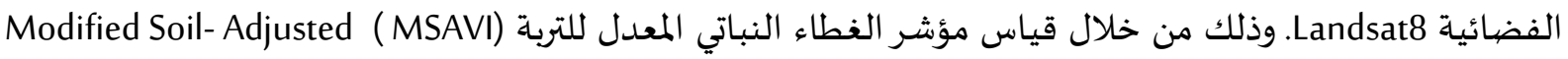

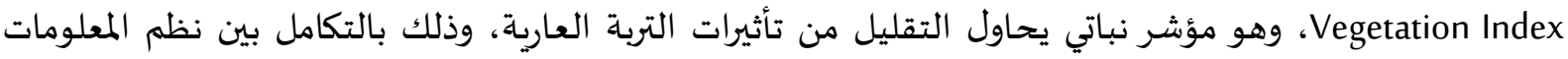
الجغرافية والاستشعار عن بعد، وذلك للوقوف على الوضع الراهن للغطاء النباتي بمنطقة الدراساة، وتتبع تغيراته،

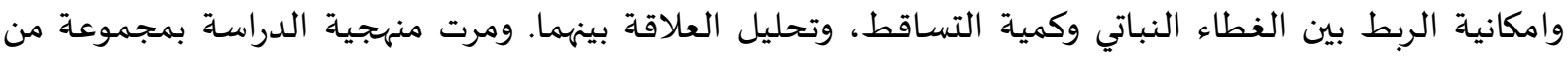
المراحل تتمثل في:

1) اختصار لVisible and Near Infrared، وهو النطاق الموجي للأشعة المرئية والأشعة تحت الحمراء القرببة، والتي تأخذ طولاً موجياً من

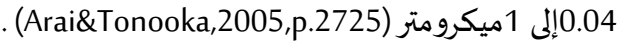
2) اختصار لـ Short Wave Infrared أي النطاق الموجي للأشعة تحت الحمراء القصيرة، والتي تأخذ طولاً موجياً من 1إلىميكرومتر (A .(Arai\&Tonooka,2005,p.2725

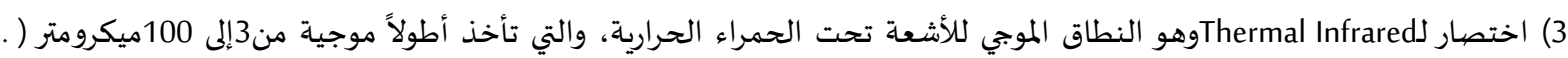
(Arail\&Tonooka,2005,p.2725 
أ- الحصيول على المرئيات الفضيائية، ومعالجتها، باعتبارها مصبدر معلومات أسـاسي لتلك الدراسة:

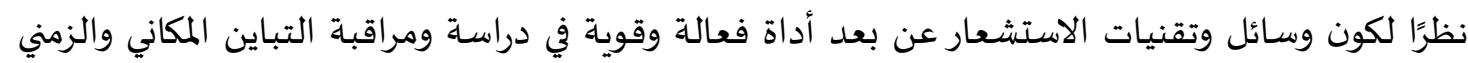

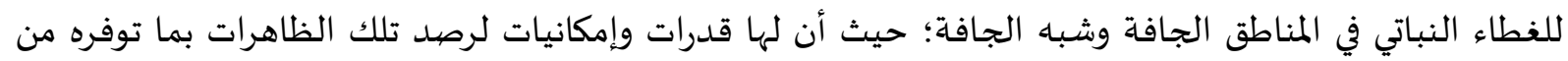

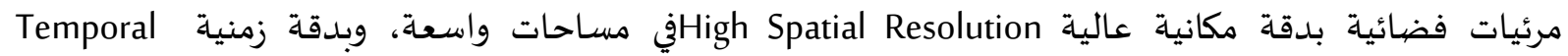
Resolution أطوال موجية مختلفة للأشعة الكهرومغناطيسية بقوة تمييز عالية، إضافة إلى معالجة تلك المرئيات باستخدام

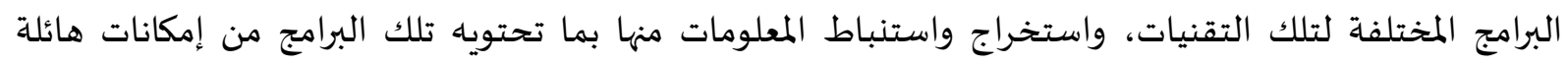
للتحليل المكاني والإحصائي. وكما يتضح من بيانات جدول (1) وجدول (2) فقد استخدمت الدراسة المرئيات الفضائية للقمر الصناعي الأمريكي لاند سات OLI على متن الجيل الثامن، كما يوضح الجدول أيضًا الخصائص الطيفية والدقة التهات المكانية للمرئيات.

وتعد المرئيات الفضائية من البيانات المكانية الرقمية، وأحد أدوات ومنتجات الاستشعار عن بعد، وتعد

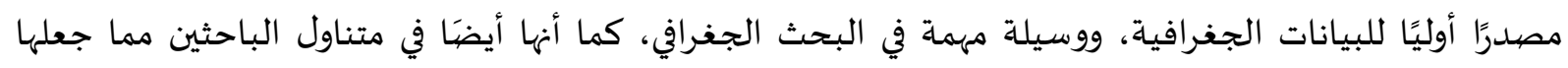

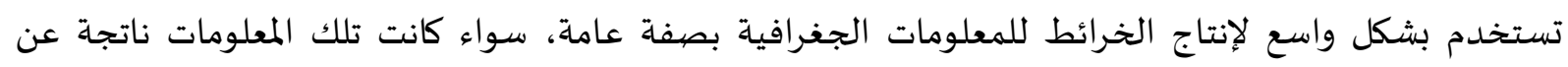

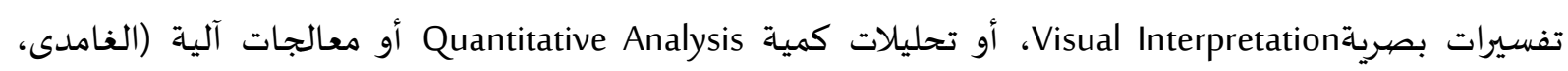

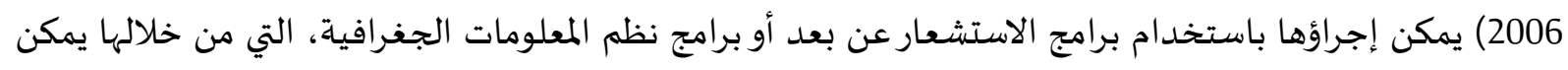

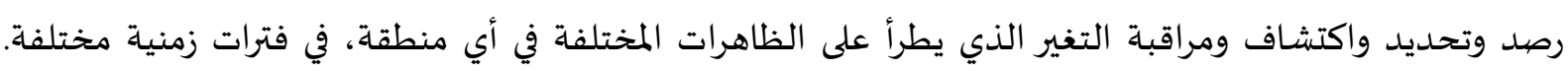
ويوضح جدول (2) لوحات المرئيات الفضائية التي اعتمدت عليها الدراسة.

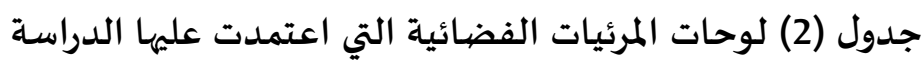

\begin{tabular}{|c|c|c|c|c|c|}
\hline المستحث & 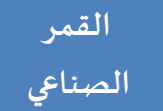 & اللوحة & نوع المثرث & اللوحة ل & 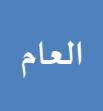 \\
\hline OLI & Landsat 8 & 167047 & Landsat 5- TM & $\begin{array}{c}\text { LC08_L1TP_167047_20140519_20200911_02_T } \\
1\end{array}$ & 2014م \\
\hline OLI & Landsat 8 & 167047 & Landsat 5- TM & $\begin{array}{c}\text { LC08_L1TP_167047_20150420_20200909_02_T } \\
1\end{array}$ & 2015م \\
\hline OLI & Landsat 8 & 167047 & Landsat 5-TM & $\begin{array}{c}\text { LC08_L1TP_167047_20160305_20200907_02_T } \\
1\end{array}$ & 2016م \\
\hline OLI & Landsat 8 & 167047 & Landsat 8- OLI & LC08_L1TP_167047_20170409_20200904_02_T & 2017م \\
\hline OLI & Landsat 8 & 167047 & Landsat 8- OLI & $\begin{array}{c}\text { LC08_L1TP_167047_20180514_20200901_02_T } \\
1\end{array}$ & 2018م \\
\hline
\end{tabular}

ب- المعالجات الأولية للمرئيات الفضيائية Image Processing: يقصد بمعالجة المرئيات الفضائية هى عملية تحسين وتنقيح للصيور وتغيير في بعض خصاتيه الفيائصها لإظهار

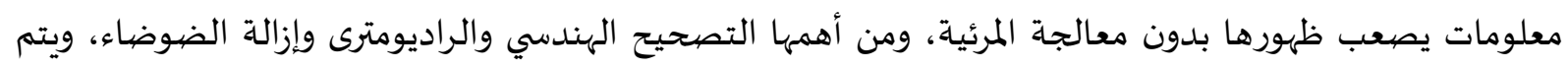

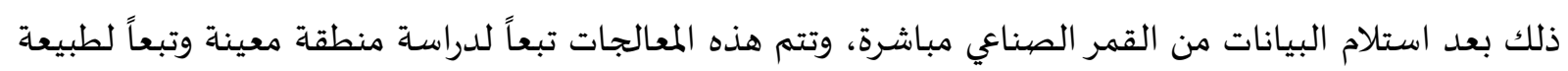


تحليل المستخدم للبيانات (Gao. 2009.p.8). وتم معالجة بيانات المرئيات الفضائية Landsat8 المستخدمة في الدراسة عن طريق المعايرة الطيفية Radiometric Calibration. ويقصد بالمعايرة الطيفية معالجة التشوهات الإشعاعية التي تنتج إما عن أخطاء استجابة أحد أجهزة

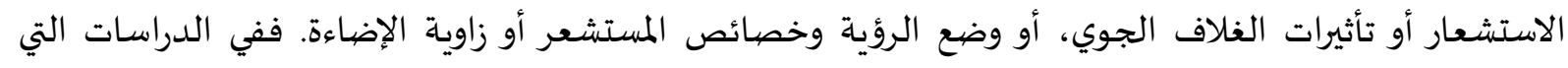

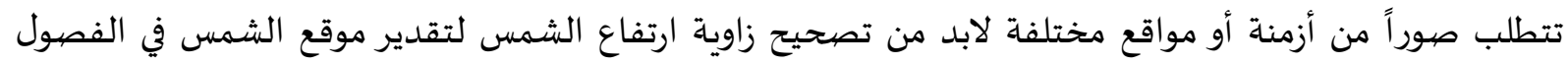

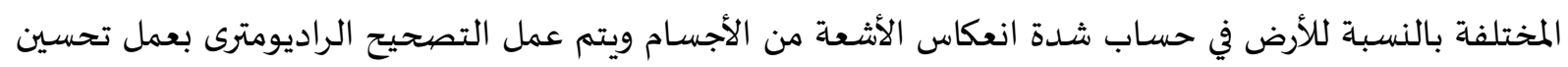
الصورة Image Enhancement.

وللغلاف الجوي تأثير كبير على أنماط الاستجابة الطيفية، فعندما تسقط الأشعة على سطح الأرض يحدث

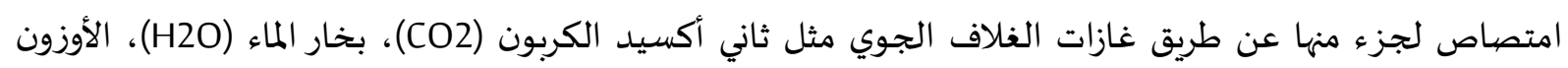

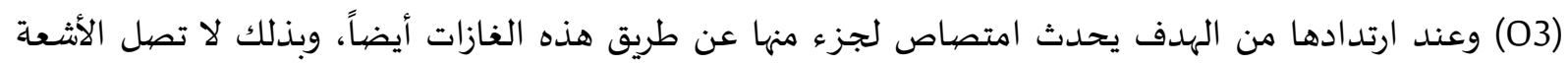

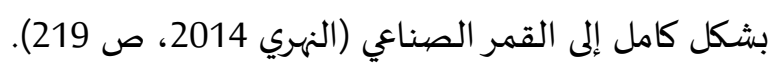
ويتسبب الغلاف الجوي في تقليل الطاقة الشمسية التي ترد إلى الهدف الأرضي كما أنه يقوم بدور عاكس للطاقة

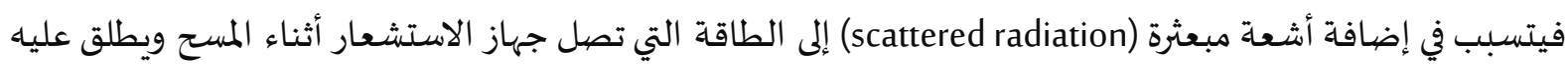

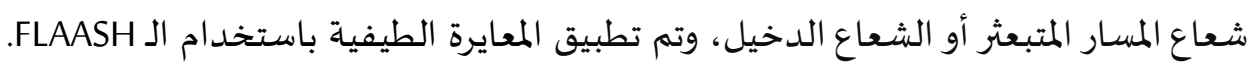

\section{ج- حساب مؤشر الغطاء النباتي المعدل للتربة (MSAVI) :}

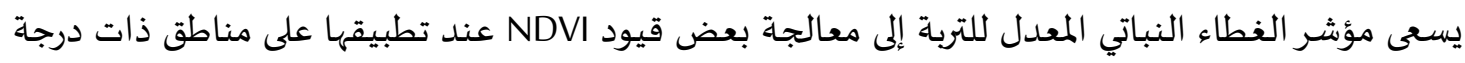

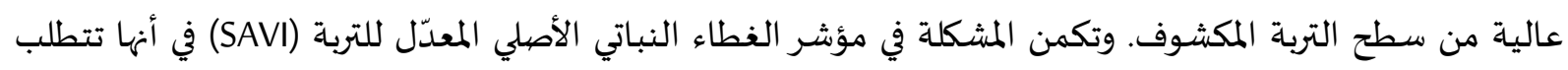
تحديد عامل تصحيح سطوع التربة (L) من خلال التجربة والخطأ بناءً على كمية الغطاء النباتي في منطقة الدراسـة.

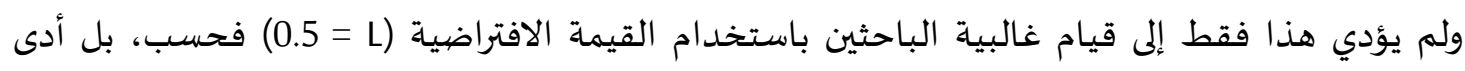

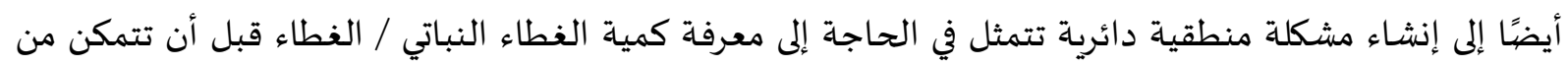

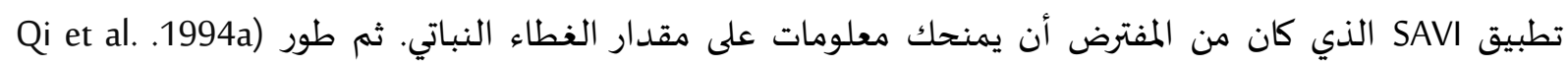
MSAVI( وبساطة. وتم حسـاب مؤشر الغطاء النباتي المعدل للتربة من المعادلة التالية:

\section{MSAVI $=\frac{(\mathrm{NIR}-\mathrm{RED})(1+\mathrm{L})}{\mathrm{NIR}+\mathrm{RED}+\mathrm{L}}$}

حيث أنRED= النطاق الطيفي الرابع (B4)، NIR= النطاق الطيفي الخامس (B5)، L= عامل تصحيح سطوع

التربة (0.5)

وثبت فيزيائيًا أن النباتات عالية الكلوروفيل تشتت نسبة 80- 90\% من النطاق الطيفي الأحمر المرئي Red،

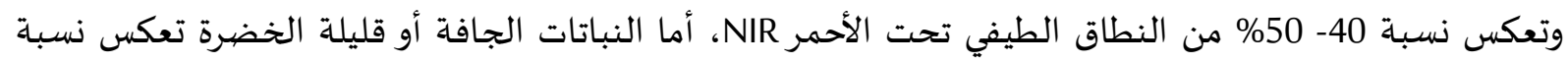

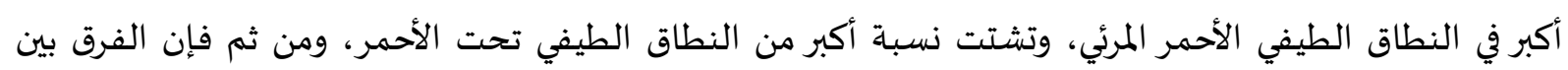

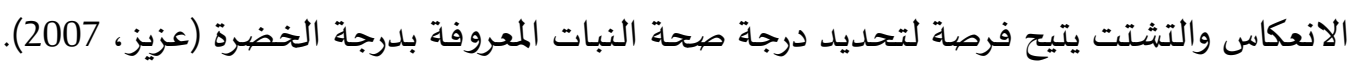

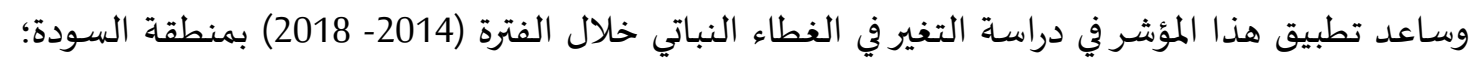
حيث تم تطبيقه على مرئيات القمر الصناعي الامريكي لاند سات في الأعوام التالية (2014- 2015- 2016- 2017- 
2018) التي تم الحصول عليها لمنطقة الدراسـة، وظهرت نتائجهاء بانعكاسية عالية في مناطق الغطاء النباتي الكثيف،

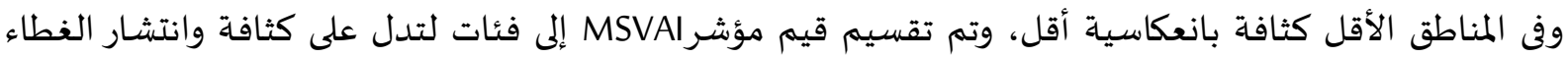

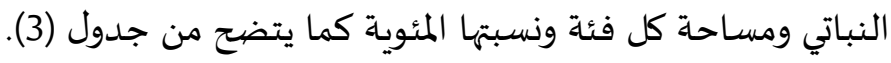

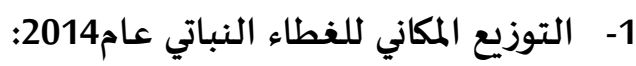
يتضح من قراءة شكل (2) وجدول (3) أن مساحة الغطاء النباتي بمنطقة السودة في الفئة أقل من صفر

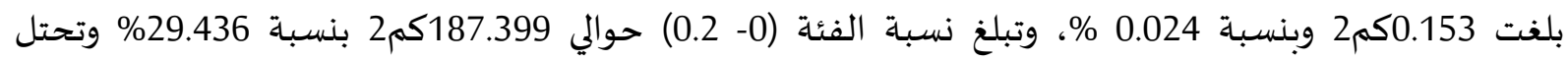

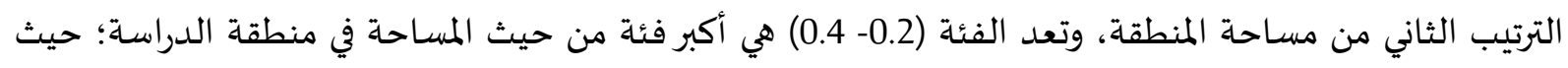

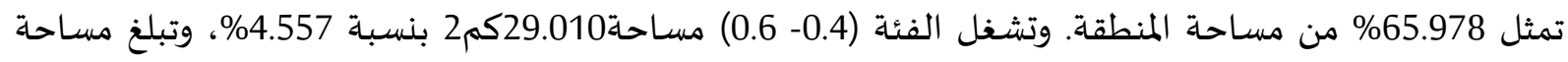

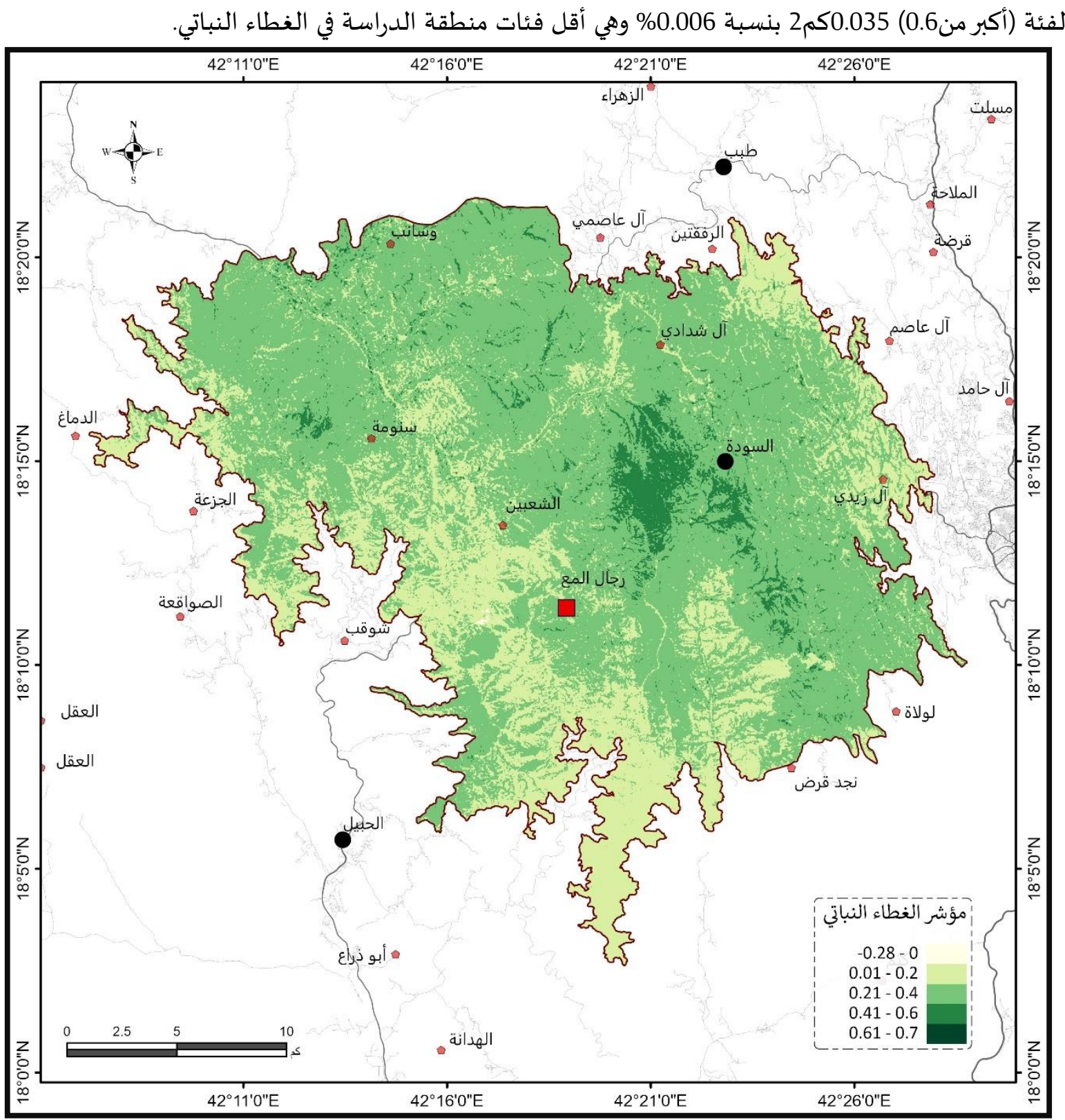

شكل (2) مؤشر الغطاء النباتي بمنطقة الدراسة عام (2014) 
2- 2 - التوزيع المكاني للغطاء النباتي عام2015: يتضح من تفسير شكل (3) وجدول (3) أن مساحة الغطاء النباتي بمنطقة السودة عام 2015بلغت في الفئة أقل من صفر 0.002كم2 فهي نسبة قليلة بالنسبة لباقي الفئات، وتبلغ نسبة الفئة (0- 0.2) حوالي

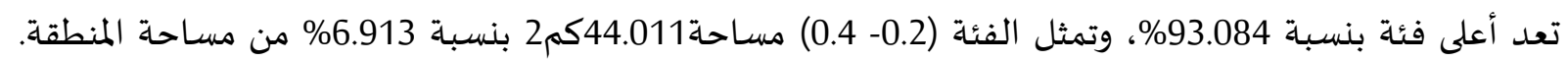

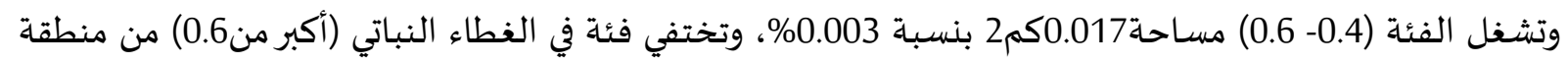
الدراسة عام 2015بالرغم أهها كانت موجودة بمساحة قليلة عام 2014.

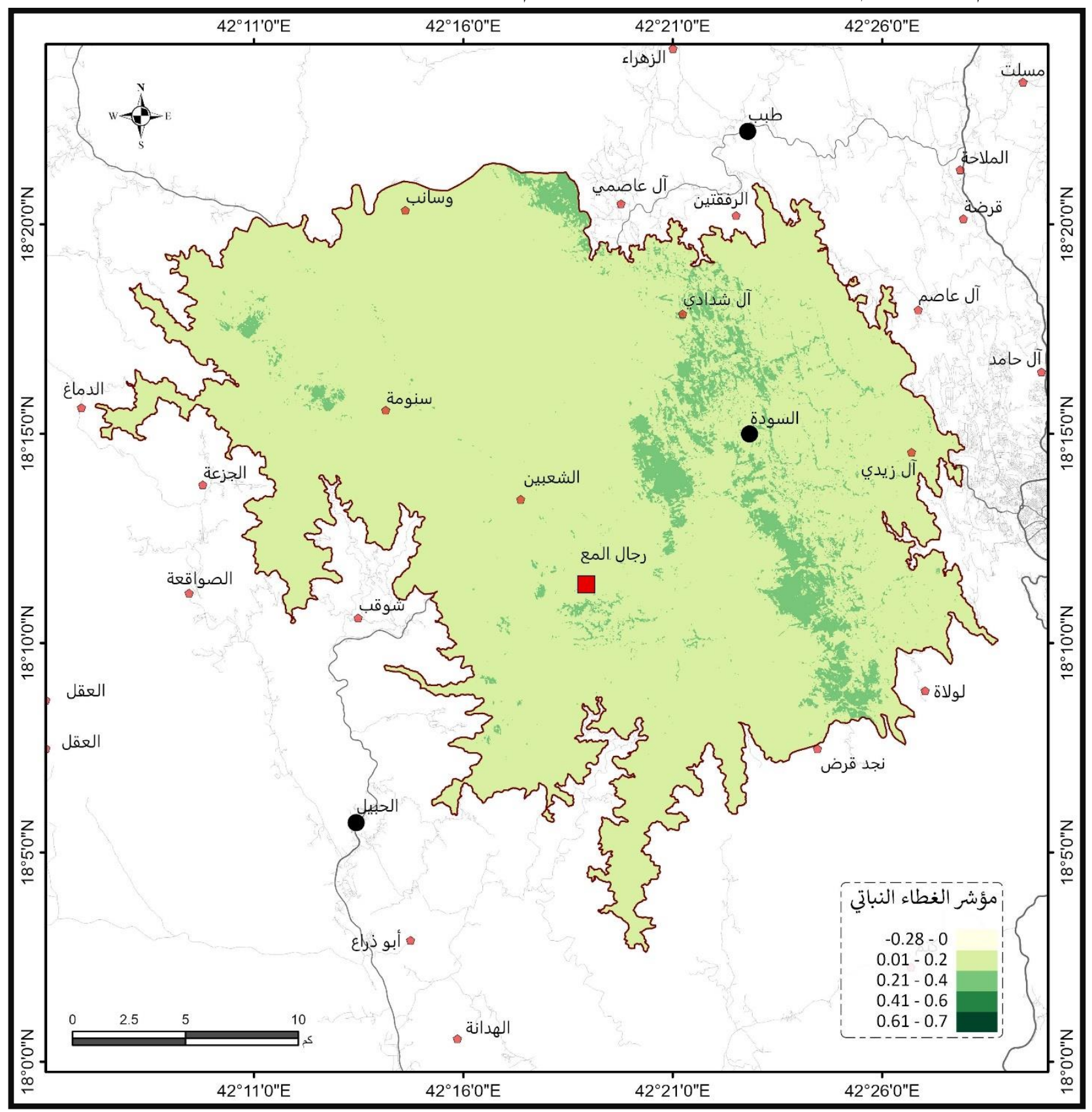

شكل (3) مؤشر الغطاء النباتي بمنطقة الدراسة عام (2015) 
جدول (3) فئات الغطاء النباتي ونسبتها بمنطقة الدراسة في الأعوام (2014، 2015، 2016، 2017، 2018)

\begin{tabular}{|c|c|c|c|c|c|c|c|c|c|c|}
\hline \multicolumn{2}{|c|}{ 2018 } & \multicolumn{2}{|c|}{ 2017 } & \multicolumn{2}{|c|}{ 2016 } & \multicolumn{2}{|c|}{ 2015م } & \multicolumn{2}{|c|}{ 2014 } & \multirow[b]{2}{*}{ الفئة } \\
\hline $\begin{array}{c}\text { النسبة } \\
\text { (\%) }\end{array}$ & (كمم2) & النسببة & المساحة) & النسببة & (كم22) & النسببة & (كمم2) & النسببة & (كم2) & \\
\hline 0.000 & 0.003 & 0.006 & 0.037 & 0.033 & 0.212 & 0.000 & 0.002 & 0.024 & 0.153 & أقل من \\
\hline 39.674 & 252.583 & 6.522 & 41.522 & 66.779 & 425.139 & 93.084 & 592.609 & 29.436 & 187.399 & $0.2-0$ \\
\hline 59.750 & 380.389 & 84.097 & 535.395 & 32.947 & 209.752 & 6.913 & 44.011 & 65.978 & 420.042 & $\begin{array}{l}-0.2 \\
0.4\end{array}$ \\
\hline 0.575 & 3.664 & 9.370 & 59.652 & 0.241 & 1.533 & 0.003 & 0.017 & 4.557 & 29.010 & $\begin{array}{l}-0.4 \\
0.6\end{array}$ \\
\hline 0.000 & 0.001 & 0.005 & 0.032 & 0.000 & 0.003 & 0.000 & 0.000 & 0.006 & 0.035 & أكبر من \\
\hline 100 & 636.639 & 100 & 636.639 & 100 & 636.639 & 100 & 636.639 & 100 & 636.639 & الاجمالى \\
\hline
\end{tabular}

3- التوزيع المكاني للغطاء النباتي عام2016:

يتضح من قراءة شكل (4) وجدول (3) أن مساحة الغطاء النباتي بمنطقة السودة عام 2016بلغت في الفئة أقل من صفر مساحة 0.212كم2 بنسبة 0.033\% من مساحة المنطقة، وتبلغ مساحة الفئة (0- 0.2) حوالي 425.139 كم2 التي تعد أعلى فئة بنسبة 66.779\%، ولكنها انخفضت عن من مساحة 2015، وتمثل الفئة (0.2- 0.4) مساحة209.752كم2 بنسبة 32.947\% من مساحة المنطقة. وتشغل الفئة (0.4- 0.6) مساحة 1.533كم2 بنسبة 0.241\%، وتمثل فئة (أكبر من0.6) في الغطاء النباتي مساحة 0.003 كمر2 عام 2016. 


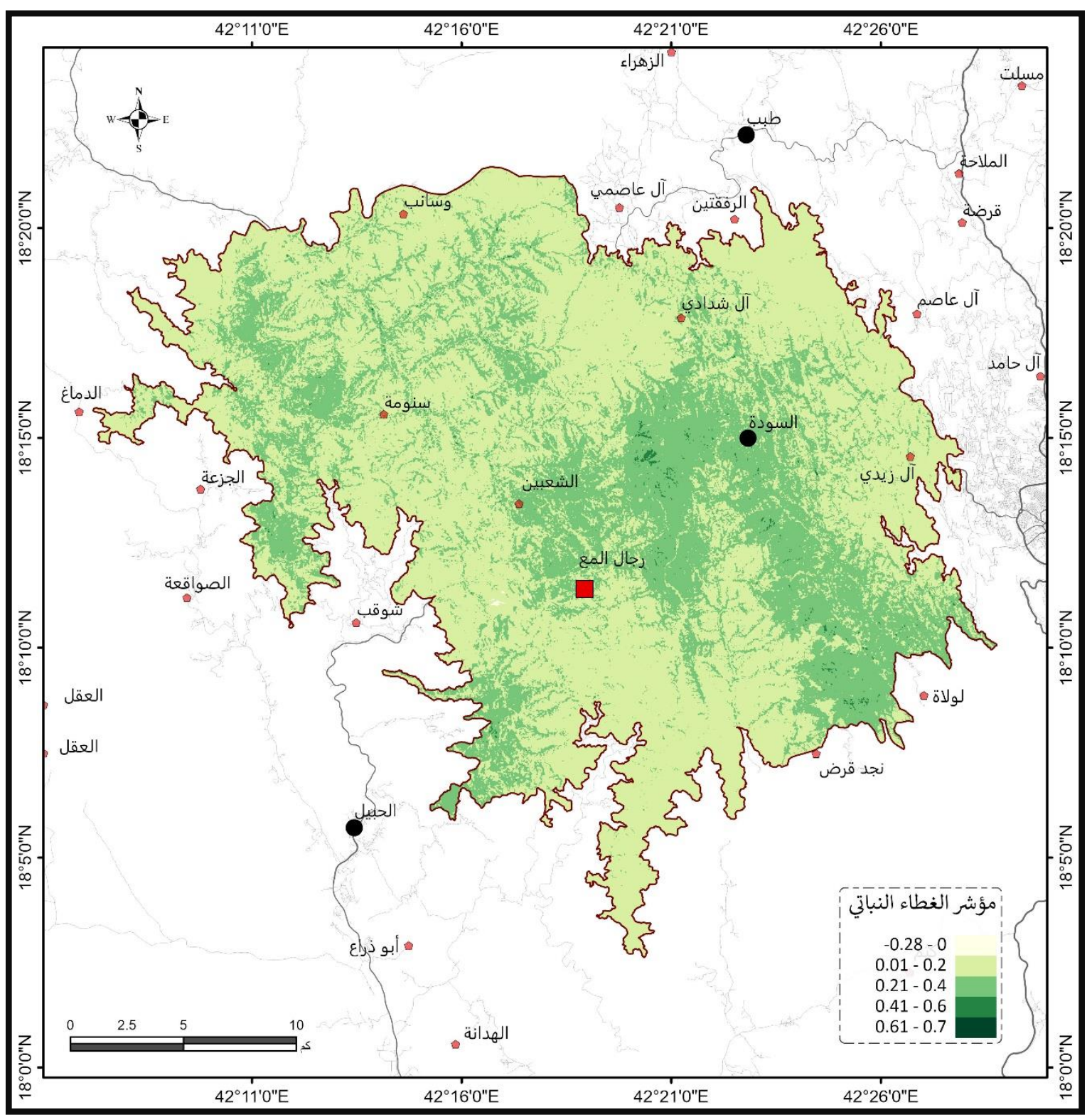

شكل (4) مؤشر الغطاء النباتي بمنطقة الدراسة عام (2016)

4- - التوزيع المكاني للغطاء النباتي عام2017: يتضح من قراءة شكل (5) وجدول (3) أن مساحة الغطاء النباتي بمنطقة السودة عام 2017في الفئة أقل من صفر بلغت مساحة 0.037كم2 بنسبة 0.006\% من مساحة المنطقة، وتبلغ نسبة الفئة (0- 0.2) حوالية

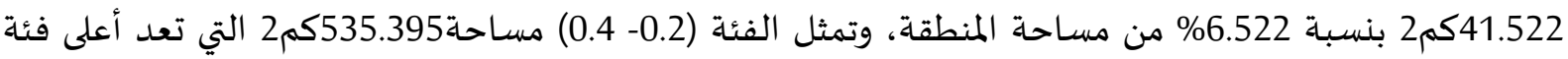
بنسبة 84.097\% من مساحة المنطقة. وتشغل الفئة (0.4- 0.6) مساحة منة مستة

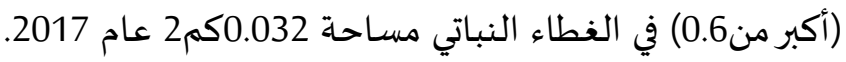




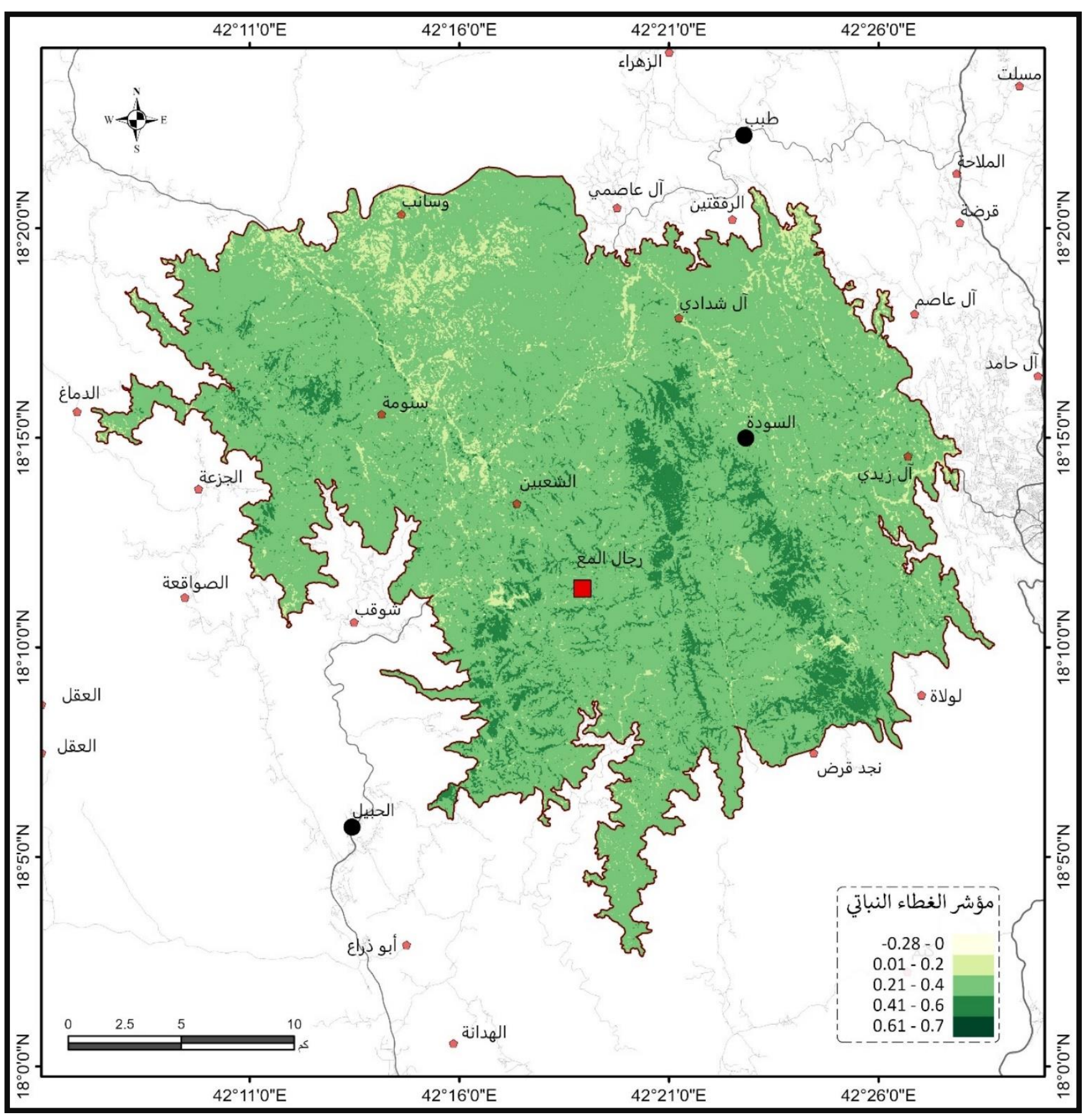

شكل (5) مؤشر الغطاء النباتي بمنطقة الدراسة عام (2017)

5- التوزيع المكاني للغطاء النباتي عام2018: يتضح من قراءة شكل (6) وجدول (3) أن مساحة الغطاء النباتي بمنطقة السودة عام 2018 في الفئة أقل من صفر بلغت مساحة 0.003كم2 من مساحة المنطقة، وتبلغ نسبة الفئة (0- 0.2) حوالي

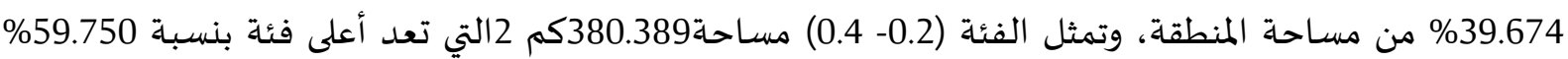

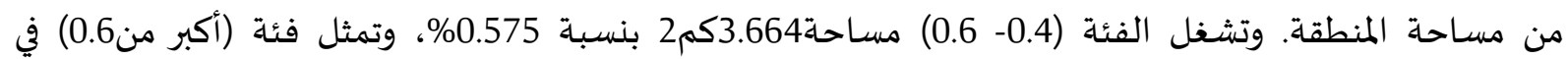
الغطاء النباتي مساحة صغيرة جدًا 0.001 كم2 عام 2018. 


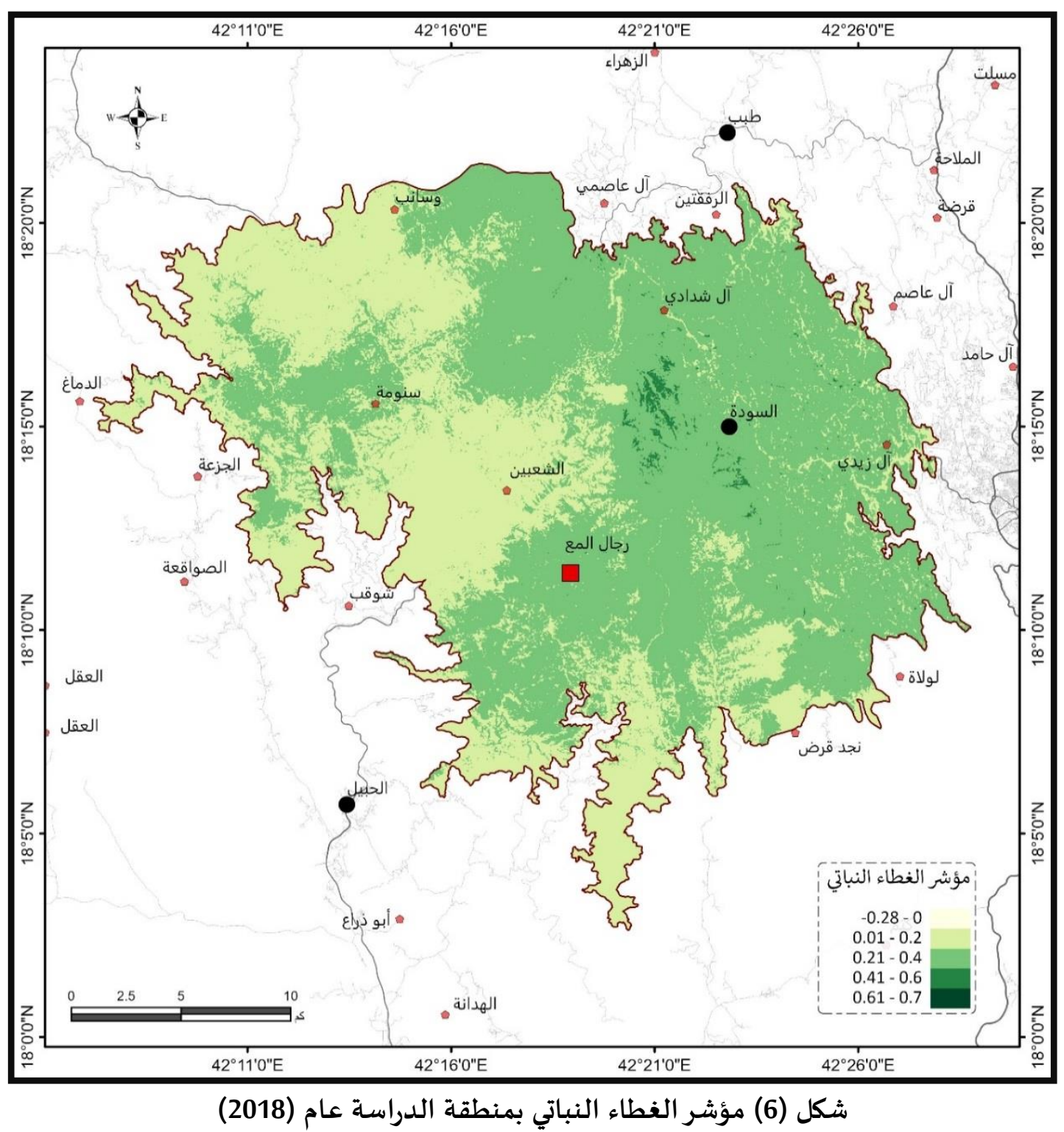

6- التباين المكاني والزمني لمساحة للغطاء النباتي عام (2018، 2017، 2016، 2015، 2014): يتضح من تحليل شكل (7) وجدول (4) الذي يوضح التغير المساحي لفئات الغطاء النباتي بمنطقة السودة، النياء

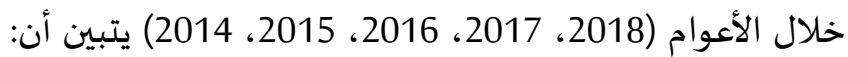
تشكل الفئتين أقل من صفر وأكبر من0.6 مساحة ضئيلة جدًا من مساحة منطقة الدراسة تكاد لا تظهر في

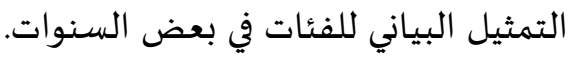

> الفئة من (0- 0.2) تقترب مساحتها من 200كم2 عام 2014، ثم تتضاعف عام عام 2015 تقترب من مساحة600كم2، ولكنها تنخفض لحوالي 400كم2 عام 2016، وتنخفض كثيرًا في عام 2017 لتقل عن من

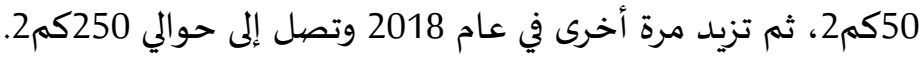

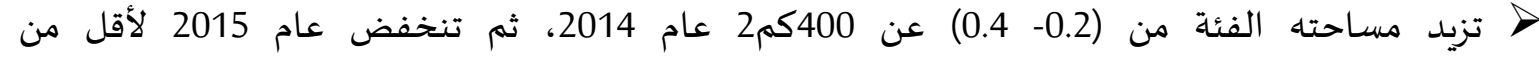

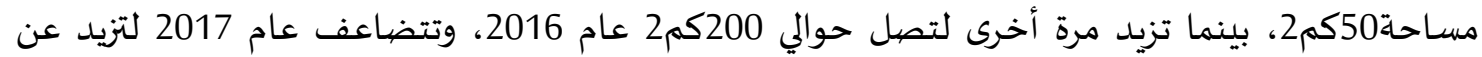

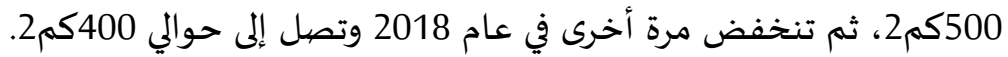


تشكل الفئة 0.4- 0.6 مساحة ليس بكبيرة من مساحة المنطقة؛ حيث وصلت مساحتها عام 2014 إلى حوالي

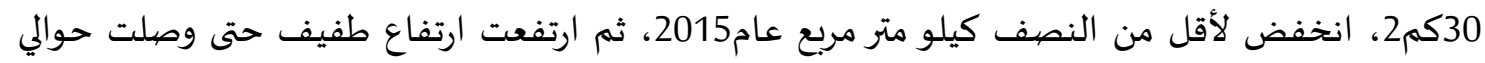

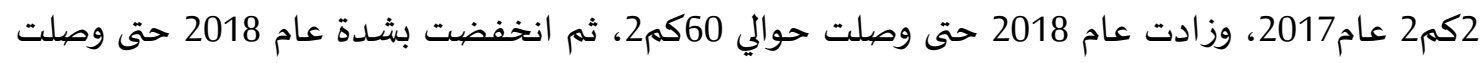

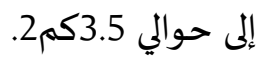

جدول (4) التغير المساحي لفئات الغطاء النباتي بمنطقة الدراسة في الأعوام (2014، 2015، 2016، 2017، (2018

\begin{tabular}{|c|c|c|c|c|c|}
\hline 2018 & 2017 & م2016 & $\hat{r}^{2015}$ & 2014 & العام \\
\hline 0.0027 & 0.036898 & 0.212386 & 0.0018 & 0.15299 & أقل من 0 \\
\hline 252.5828 & 41.52236 & 425.1392 & 592.6091 & 187.3992 & $0-0.2$ \\
\hline 380.3887 & 535.3954 & 209.7519 & 44.0107 & 420.0419 & $0.2-0.4$ \\
\hline 3.663659 & 59.65167 & 1.532599 & 0.017099 & 29.00959 & 0.4- 0.6 \\
\hline 0.0009 & 0.032398 & 0.0027 & 0 & 0.035098 & أكبر من 0.6 \\
\hline
\end{tabular}

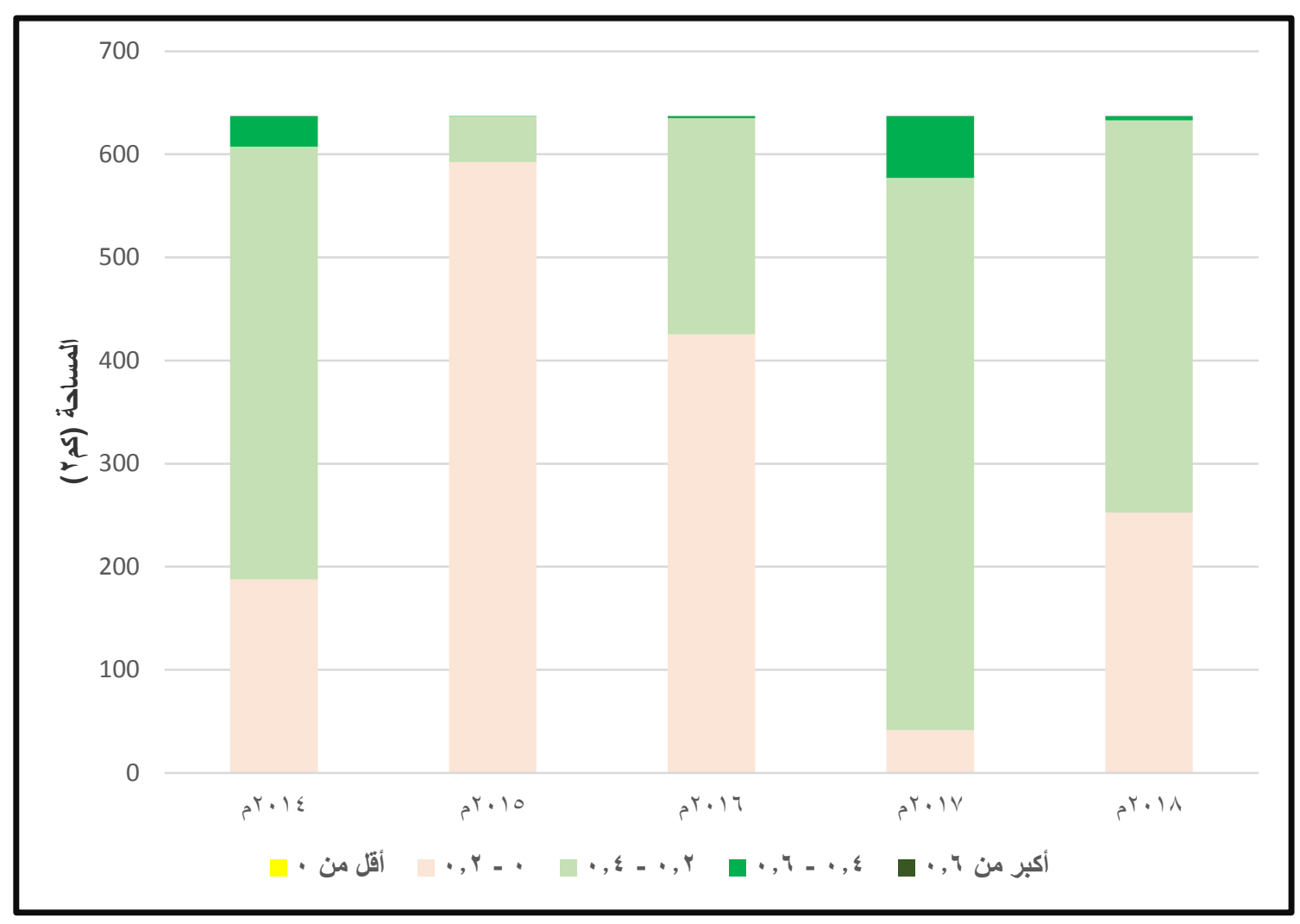

شكل (7) تباين مساحة الغطاء النباتي بمنطقة السودة في الأعوام (2014، 2015، 2016، 2017، 2018) 7- التباين المكاني والزمني لقيم الغطاء النباتي عام (2018، 2017، 2016، 2015، 2014): يتبين من تحليل جدول (5) وشكل (8) أن: المكان: 
بلغت أقل قيمة في عام 2014 حوالي- 0.291بينما بلغت أكبر قيمة0.668، وبلغ متوسط القيم 0.250، وانحرافها المعياري 0.079، بينما بلغ معامل الاختلاف بين القيم 31.664. ووصلت أقل قيمة في عام 2015 إلى- 0.026بينما بلغت أكبر قيمة 0.497، وبلغ متوسط المانيان القيم 0.137، وانحرافها المعياري عن المتوسط 0.037، بينما بلغ معامل الاختلاف بين القيم 26.962. جدول (5) التغير المكاني والزمني لقيم الغطاء النباتي بمنطقة الدراسة خلال الأعوام (2018، 2017، 2016، (2014، 2015

\begin{tabular}{|c|c|c|c|c|c|}
\hline معامل الاختلاف & الانحراف المعياري & متوسط القيم & أكبر قيمة & أقل قيمة & 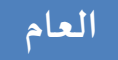 \\
\hline 31.664 & 0.079 & 0.250 & 0.668 & -0.291 & 2014م \\
\hline 26.962 & 0.037 & 0.137 & 0.497 & -0.026 & 2015م \\
\hline 30.800 & 0.057 & 0.186 & 0.630 & -0.103 & 2016م \\
\hline 24.202 & 0.072 & 0.297 & 0.696 & -0.071 & 2017م \\
\hline 27.642 & 0.061 & 0.221 & 0.613 & -0.032 & 2018م \\
\hline
\end{tabular}

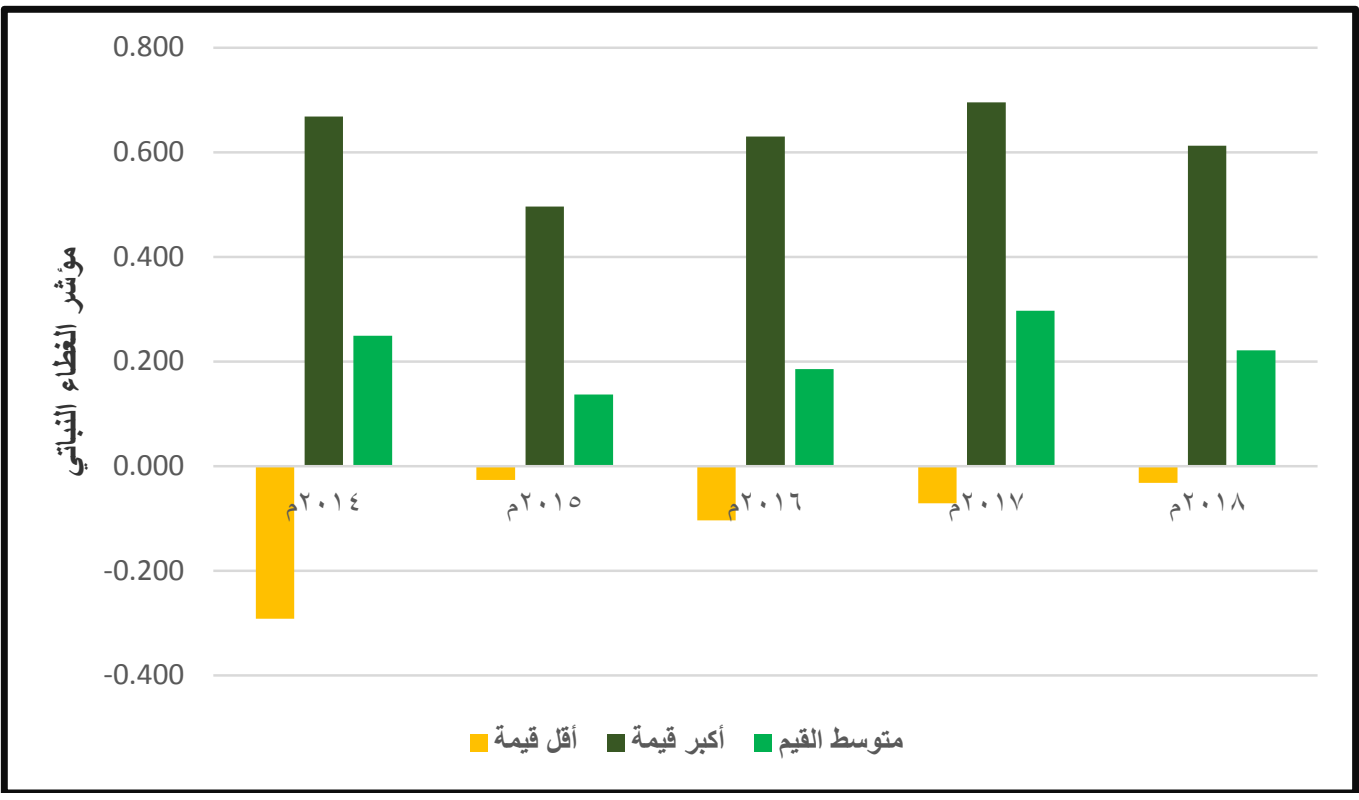

شكل (8) التغير المكاني والزمني لقيم الغطاء النباتي بمنطقة الدراسة خلال الأعوام (2018، 2017، 2016،

(2014، 2015

بلغت أقل قيمة لمؤشر الغطاء النباتي في عام 2016م (- 0.103)، بينما بلغت أعلى قيمة 0.630، بمتوسط قيم 0.186، وانحراف معياري 0.057، ووصلت نسبة الاختلاف إلى 0.000\% 30.800. وبلغت أقل قيمة المؤشر الغطاء النباتي

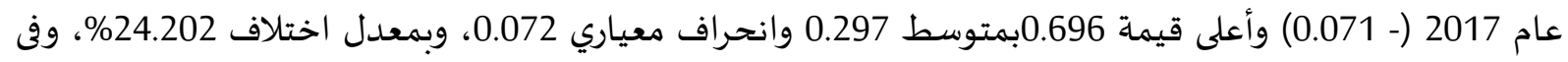

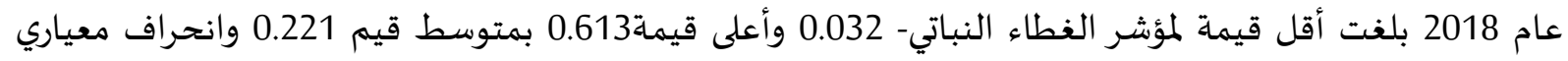
0.061، وبلغت نسبة الاختلاف 27.642\%.

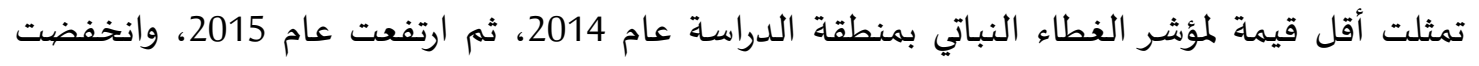

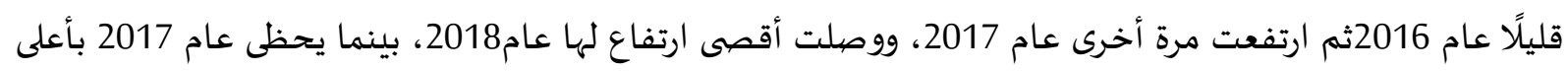


قيمة في مؤشر الغطاء النباتي، يليه في الترتيب عام 2014، ثم عامي 2016و2018، بينما عام 2015يعد أقل الأعوام من حيث أعلى قيمة لمؤشر الغطاء النباتي. ووصل أعلى متوسط لقيم مؤشر الغطاء النباتي عام2017، يليه في الترتيب عام 2014، بينما يعد عام2015 هو أقل الأعوام من حيث قيم متوسط مؤشر الغطاء النباتي.

8- التباين المكاني لمعدل التساقط السنوي بمنطقة السودة: يفسر جدول (6) المعدل الشهري والفصلي والمتوسط السنوي لمعدل التساقط بمنطقة السودة، ومن تحليل الجدول وقراءة شكل (9) يتضح أن متوسط كمية التساقط السنوي بمنطقة الدراسة يبلغ 338.7ملم، وتبلع أقصى كمية تساقط في فصلي الربيع والصيف فتصل على التوالي39.3 ملم و33.4ملم، وأقل كمية تسقط فئ في منطقة

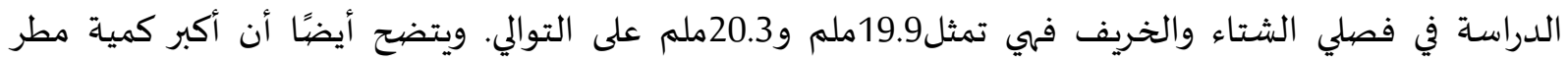
سقطت في شهر أبريل46.1ملم، وأقل كمية مطر سقطت في شهر سبتمبر 14.1ملم. جدول (6) المعدل الشهري والفصلي والسنوي لقيم التساقط بمنطقة الدراسة

\begin{tabular}{|c|c|c|c|}
\hline الفصيلي & الشهري & الفصهلي & الشهري \\
\hline \multirow{3}{*}{19.9} & 23.9 & \multirow{3}{*}{ الشتاء } & ديسمبر \\
\hline & 19.6 & & يناير \\
\hline & 16.3 & & فبراير \\
\hline \multirow{3}{*}{39.3} & 28.3 & \multirow{3}{*}{ الربيع } & مارس \\
\hline & 46.1 & & إبريل \\
\hline & 43.5 & & مايو \\
\hline \multirow{3}{*}{33.4} & 18.5 & \multirow{3}{*}{ الصيف } & يونيو \\
\hline & 41.3 & & يوليه \\
\hline & 40.2 & & أغسطس \\
\hline \multirow{3}{*}{20.3} & 14.1 & \multirow{3}{*}{ الخريف } & سبتمبر \\
\hline & 18.5 & & أكتوبر \\
\hline & 28.3 & & نوفمبر \\
\hline \multicolumn{2}{|c|}{338.7} & \multicolumn{2}{|c|}{ المتوسط السنوي } \\
\hline
\end{tabular}

المصدر: موقع World Climate الإصدار الثاني، ومصدرها: وحدة أبحاث المناخ CRU، جامعة East Anglia بإنجلترا الإصدار الرابع CRU TS v4.03 الصادر 15 من مايو لعام 2019، بدقة 2.5 دقيقة جغرافية. 


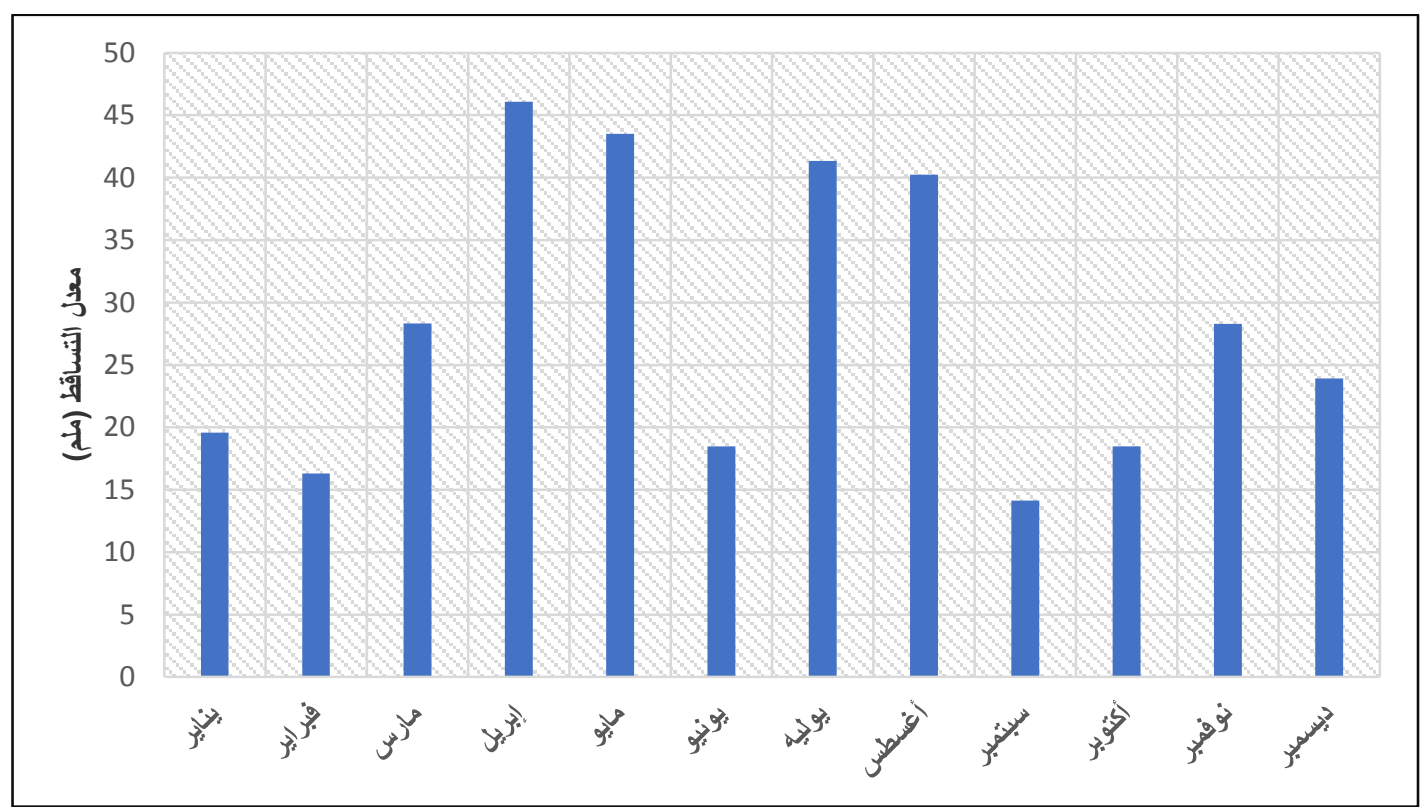

شكل (9) المعد الشهري للتساقط بمنطقة الدراسة

ومن خلال تحليل شكل (10) الذي يوضح التوزيع المكاني لمعدل التساقط بمنطقة الدراسة يتضح أن كمية

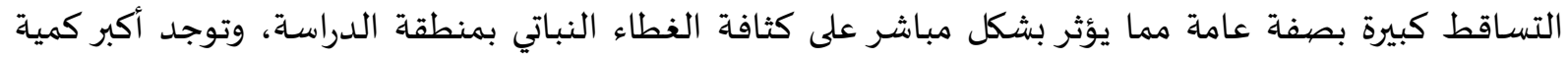
تساقط (335- 357ملم) توجد في وسط وجنوب غرب منطقة الدراسة، بينما توجد أقل كمية لمعدل التساقط في

الاطراف الشمالية والشمالية الشرقية من منطقة الدراسة (218- 240ملم).

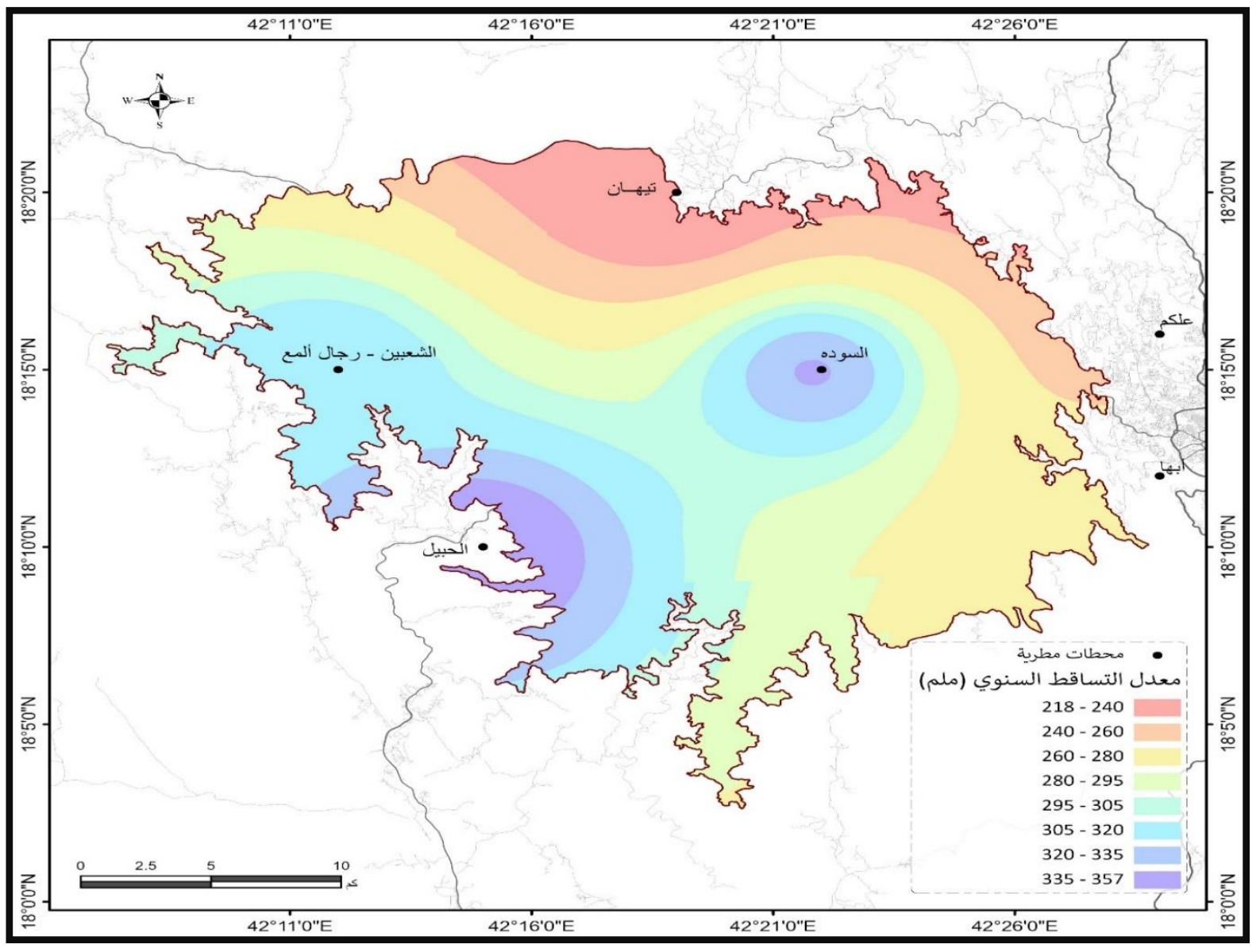

شكل (10) التباين المكاني لقيم معدل التساقط السـنوي بمنطقة الدراسة 
جدول (7) التغير المكاني لقيم معدل التساقط السنوي بمنطقة الدراسة

\begin{tabular}{|c|c|c|c|c|}
\hline معامل الاختلاف (\%) & الانحراف المعياري & متوسط القيم & أكبر قيمة & أقل قيمة \\
\hline 9.897 & 28.3 & 286.3 & 357.4 & 217.9 \\
\hline
\end{tabular}

ويتضح من قراءة جدول (7) أن أقل قيمة في المعدل السنوي للتساقط تبلغ 217.9ملم، وتبلغ أكبر قيمة

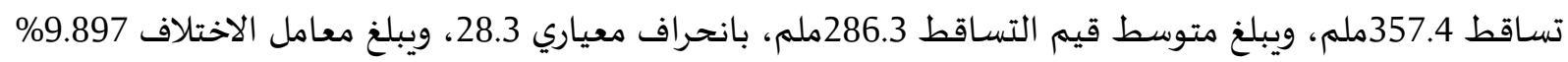

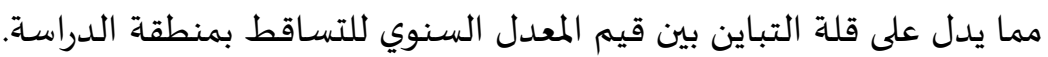

9- التباين المكاني والزمني لقيم الغطاء النباتي خلال الفترة (2014- 2018):

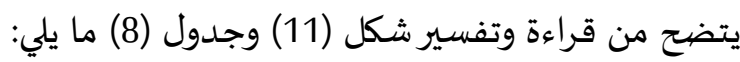

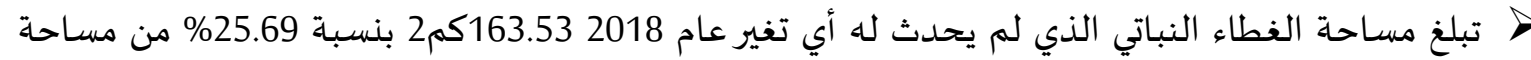
منطقة الدراسة. > تمثل مساحة الأراضي الجرداء التي لم يحدث لها تغير 318.47كم2 بنسبة 50.02\% من مساحة منطقة الدراسـة، أي أن حوالي نصف المساحة الاضي كانت تمثل حوالي 50\% من مساحة المنطقة ولم يحدث لهاء لها أي تغيير.

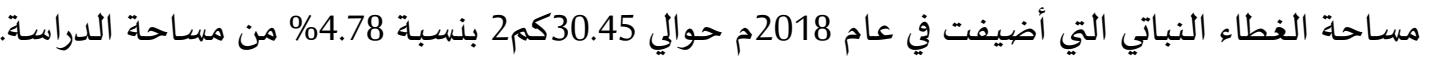

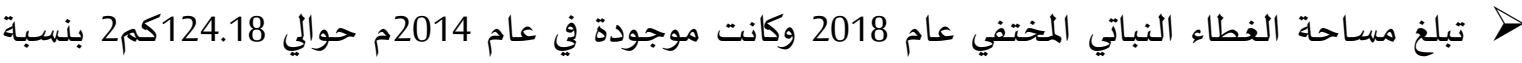
19.51\% من مساحة منطقة الدراسة، وربما يرجع ذلك إلى التوسعات في التنمية السياحية في هذه الفترة.

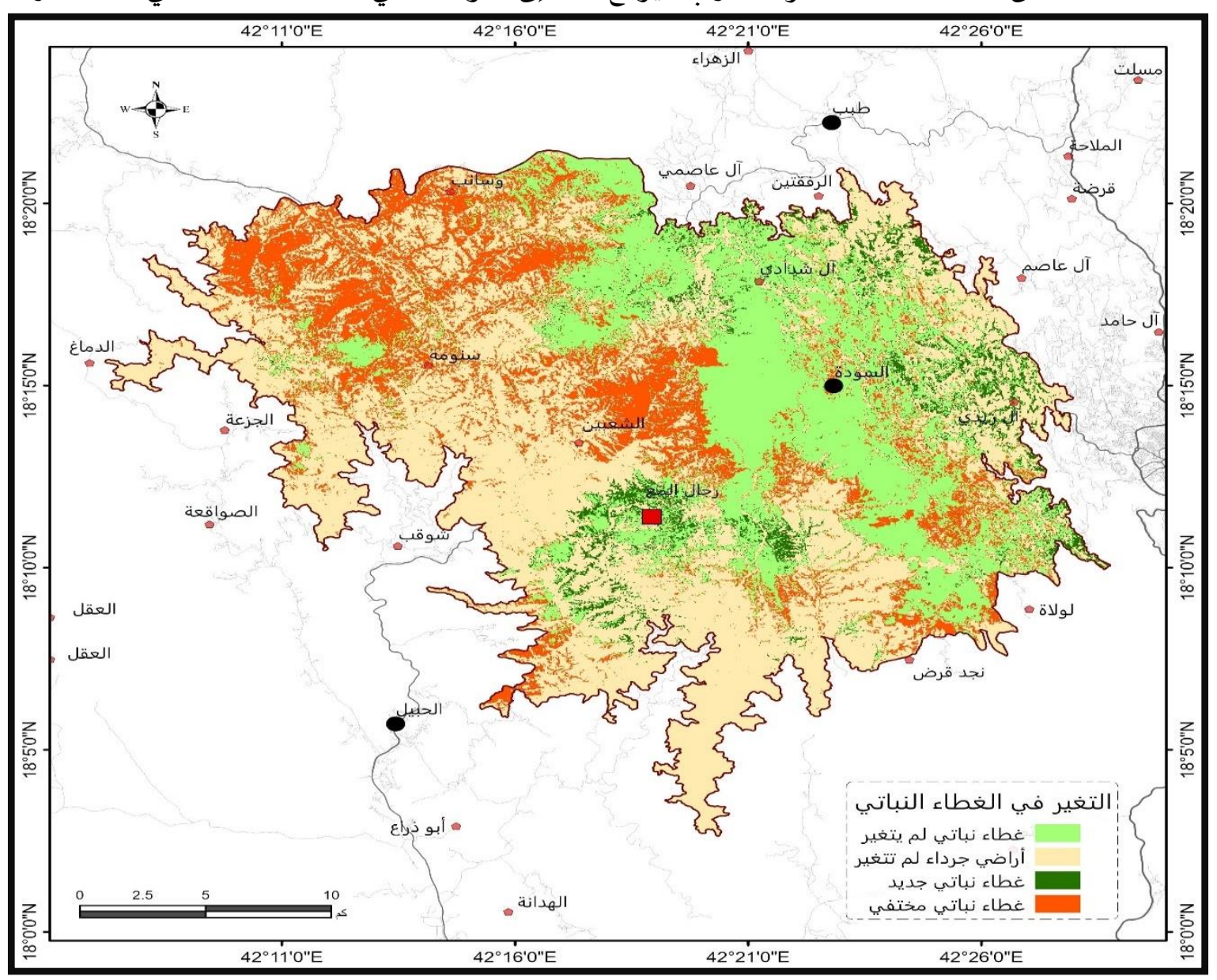

شكل (11) التغيرفي الغطاء النباتي خلال الفترة (2014- 2018م) 
جدول (8) فئات تغير الغطاء النباتي خلال الفترة (2014- 2018)

\begin{tabular}{|c|c|c|}
\hline النسبة (\%) & المسياحةة (كم2) & التصنيف \\
\hline 25.69 & 163.53 & غطاء نباتي لم يتغير \\
\hline 50.02 & 318.47 & أراضي جرداء لم تتغير \\
\hline 4.78 & 30.45 & غطاء نباتي جديد \\
\hline 19.51 & 124.18 & غطاء نباتي مختفي \\
\hline
\end{tabular}

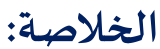

(MSAVI) Modified Soil- Adjusted Vegetation Indexناقش البحث مؤشر الغطاء النباتي المعدل للتربة بمنطقة السودة عن طريق التكامل بين تقنيتي الاستشعار من البعد ونظم المعلومات الجغرافية واستخدام المرئيات الفضائية الفLا في الأعوام التالية (2014، 2015، 2016، 2017، 2018) والتي تم معالجتها وتخزينها في قاعدة البيانات الجغرافياة، حتى يتم احتساب المساحات وإخراج الخرائط النهائية. وخلص البحث إلى أن هناك تغيرات في الغطاء النباتي بمنطقة السودة، وقد تم رصده خلال فترات الدراسة، وبعض التغيرات في الغطاء النباتي بالسلب والبعض الآخر بالإيجاب، وتبعًا لذلك توصل إلى عدة نتائج يمكن توضيحها فيما يلى: استخدام وسائل وتقنيات الاستشعار عن بعد ونظم المعلومات الجغرافية وفرت الكثير من الوقت والجهد والتكلفة في رصد التغير في الغطاء النباتي.

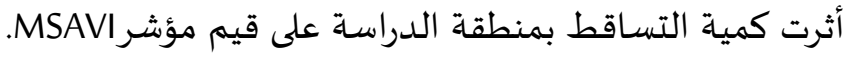
تناقصت مساحة الغطاء النباتي خلال الفترة (2014- 2018)؛ حيث أنه توجد مساحات من الغطاء النباتي اختفت عام 2018. يعتبر مؤشر الغطاء النباتي المعدل للتربة (MSAVI) من أفضل المؤشرات المستخدمة في استخلاص الغطاء النباتي. قائمة المراجع

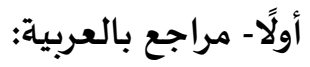

1- - أبو علي، نافز محمود (2016): كشف التفير في غطاء الأرض واستعمالاتها في لواء وادي السير خلال الفترة (1989- 2014) باستخدام نظم المعلومات الجغرافية والاستشعار عن بعد، رسالة ماجستير، عمادة الدراسات العليا، جامعة مؤتة. 2- دويدار، خالد محمود (2013): تقييم فاعلية المؤشرات النباتية الطيفية في تقدير خصائص الغطاء النباتي الطبيعي من بيانات الاستشعار عن بعد في شمال جبال السروات، رسالة دكتوراه، كلية العلوم الاجتماعية، جامعة الإمام محمد بن سعود الإسلامية. 3- الرحيلي، بسمة بنت سلامة بن سالم (2013): توظيف تقنية الإستشعار عن بعد لمراقبة وكشف المبف التغير في

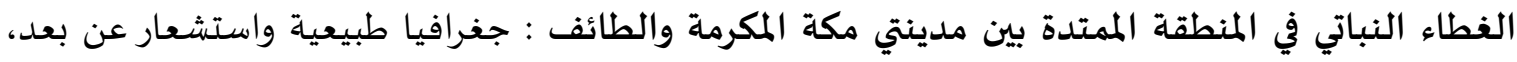

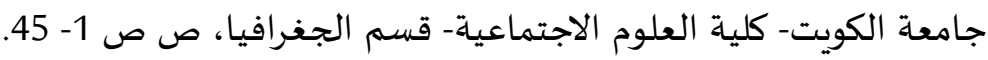


4- الصالح، عبدالله بن عبدالمحسن بن عبدالله (2006): الخصبائص النباتية لمجتمع العرعر Juniperus procera

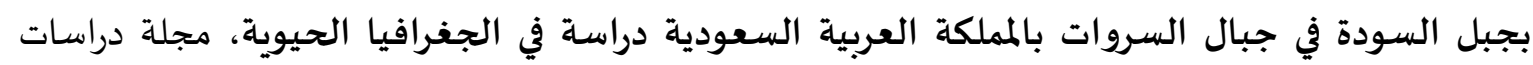

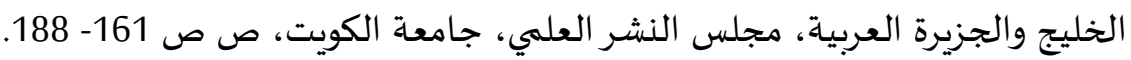

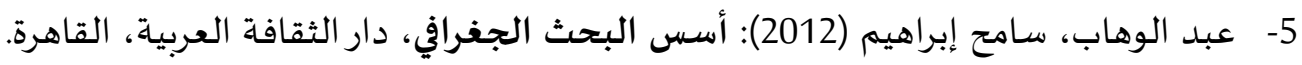

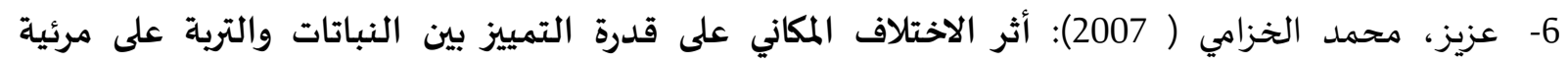

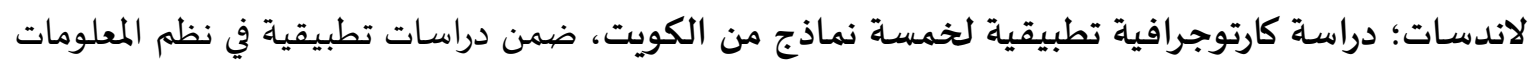

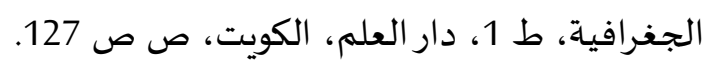
7- الغامدي، سعد أبوراس (2006 ): توظيف نظم المعلومات الجغرافية في استخراج بعض المض القياسات المورفومترية من نماذج الارتفاعات الرقمية، دراسة حالة وادي ذري في السعودية، رسائل جغرافية، الجمعية الجغرافية الكويتية. 8- المتولى، وائل محمد وحسن، سلطان الفولى وعابدين، ممدوح (2017): مؤشر جودة الغطاء النباتي (VQI) في

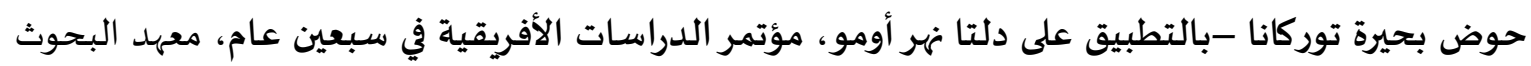

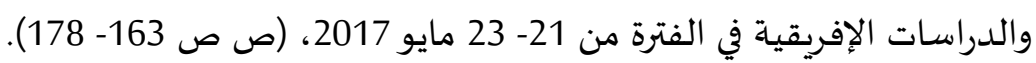

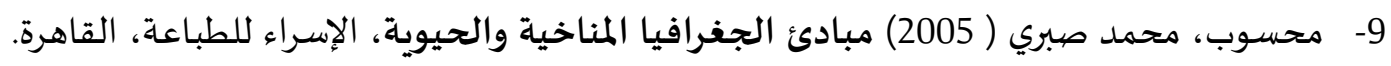

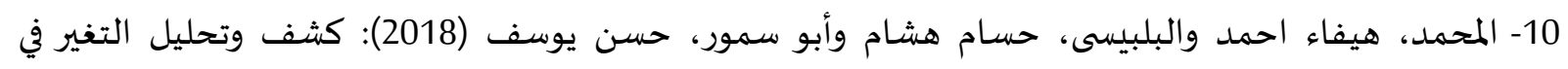

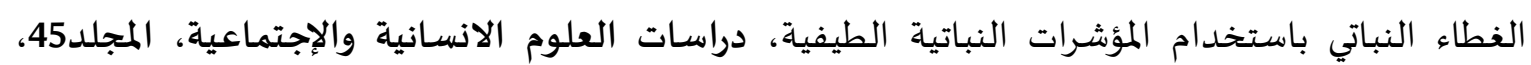

$$
\text { 11- الهري، علاء الدين حسن ص صد (2014): علم الاستشعار عن بعد، بدون ناشر، القاهرة. }
$$

ثانيًا: مراجع باللغة الأجنبية:

1- Arail,K. \& Tonooka, H. (2005): Radiometric Performance Evaluation of ASTER VNIR,SWIR, and TIR. IEEE Geoscience and Remote Sensing Society.Vol.43. (12), pp.2725- 2732.

2- Epiphanio, J.C., Gleriani, J.M. and Rudoroff, B.F.( (1996) :Vegetation Indices for Remote Sensing of Beans (Phaseaolus Valgansi). Pesquisa Agropecu Aria Barasileira, Vol. 31, No. 6, pp.445- 454.

3- Gao, J. (2009): Digital Analysis Of Remotely Sensed Imagery, Ph.D School of Geography, Geology and Environmental Science, The University of Auckland, Auckland, New Zealand.

4- Jensen, P.L. and Huete, A.R. (2001) :Assessment of Spectral Vegetation Indices for Riparian Vegetation in the Colorado River Delta. Mexico, J. of Arid Environment, Vol.49, No.1, pp.91-110.

5- Penuelas, J. and Araus, A. (1997): Visible and Near Infrared Reflectance Assessment of Salinity Effected on Barley. Crop Science, (USA). Vol. 371, No. 1, pp.198-202.

6- Pour, A.B.\& Hashim, M. (2015): Hydrothermal Alteration Mapping from Landsat8 Data, Sar Cheshmen Copper Mining District, South -Eastern Islamic Republic of Iran, Journal of Taibah University for Science. Vol. 9, PP.155- 166

7- Qi J., Chehbouni A., Huete A.R., Kerr Y.H.(1994) Modified Soil Adjusted Vegetation Index (MSAVI). Remote Sens Environ 48:119-126. 
8- Shrestha, D.P. and Zink, J.A. (2001): Land Use Classification in Mountainous Area: Integration of Image Processing, Digital Elevation Date and Field Knowledge an Application in Nepal. ITC. Enscheda. Netherlands, pp.1-14.

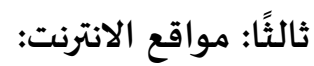

1- http://earthexplorer.usgs.gov/

2- https://www.argaam.com/ar/article/articledetail/id/1446182

3- https://wiki.orfeo- toolbox.org/index.php/MSAVI 